\title{
əInvestigating the Role of the Tibetan Plateau in ENSO Variability
}

\author{
QIN WEN \\ Laboratory for Climate and Ocean-Atmosphere Studies and Department of Atmospheric and Oceanic Sciences, School of \\ Physics, Peking University, Beijing, China, and Department of Meteorology (MISU), Stockholm University, \\ Stockholm, Sweden \\ KRISTOFER DÖÖS \\ Department of Meteorology (MISU), Stockholm University, Stockholm, Sweden \\ ZHENGYAO LU \\ Department of Physical Geography and Ecosystem Science, Lund University, Lund, Sweden \\ ZIXUAN HAN \\ College of Atmospheric Sciences, Lanzhou University, Lanzhou, China, and Department of Physical Geography and Bolin \\ Centre for Climate Research, Stockholm University, Stockholm, Sweden

\section{HAIJUN YANG} \\ Laboratory for Climate and Ocean-Atmosphere Studies and Department of Atmospheric and Oceanic Sciences, School of \\ Physics, Peking University, Beijing, China
}

(Manuscript received 10 June 2019, in final form 3 February 2020)

\begin{abstract}
The role of the Tibetan Plateau (TP) in El Niño-Southern Oscillation (ENSO) variability is investigated using coupled model experiments with different topography setups. Removing the TP results in weakened trade winds in the tropical Pacific, an eastward shift of atmospheric convection center, a shallower mixed layer in the equatorial Pacific, and a flattened equatorial thermocline, which leads to an El Niño-like sea surface temperature (SST) response. In association with these mean climate changes in the tropical atmosphereocean system, the ENSO variability exhibits a much stronger amplitude in the world without the TP. Detailed diagnoses reveal that in the absence of the TP, both thermocline feedback in the eastern equatorial Pacific and Ekman pumping feedback in the central-eastern equatorial Pacific are enhanced substantially, leading to stronger ENSO variability. The changes of these two feedbacks are caused by the eastward shift of the atmospheric convection center and enhanced ocean sensitivity; the latter is due to the shallower mixed layer and flattened thermocline. This study suggests that the presence of the TP may be of fundamental importance for modern-day tropical climate variability; namely, the TP may have played a role in suppressing ENSO variability.
\end{abstract}

\section{Introduction}

The uplift of the Tibetan Plateau (TP) was a major tectonic event that occurred during the Late Cenozoic (Molnar et al. 1993; Ruddiman and Kutzbach 1989). Paleoclimatic

๑ Denotes content that is immediately available upon publication as open access.

Corresponding author: Haijun Yang, hjyang@pku.edu.cn proxy data show that the TP uplift induced a shift in atmospheric jet stream and formation of large continental ice sheets in both hemispheres (Ruddiman and Kutzbach 1989), and a lower atmospheric $\mathrm{CO}_{2}$ concentration and thus a global cooling (Raymo and Ruddiman 1992). The accelerated uplift of the TP can be traced back to 10-8 million years ago (Ma) (Harrison et al. 1992; Molnar et al. 1993). The proxy records from China and marine sediment data from the Indian and North Pacific Oceans suggest that the establishment of the 
Indian and East Asian monsoon systems, and the progressively drier winter over the northern Great Plains and the Eurasian interior, can be attributed to the rapid TP uplift about 9-8 Ma (Ruddiman and Kutzbach 1989; An et al. 2001). The uplift of the TP may also have led to the enhanced draining at the southern side of the Himalayan-Tibetan orogen about 9 Ma (Ruddiman 2013), the major dust peak from Asia to the North Pacific about 8-7 Ma (Rea et al. 1998), and changes in vegetation from forests to grasses about $8 \mathrm{Ma}$ (Cerling et al. 1997).

El Niño-Southern Oscillation (ENSO) is the most prominent interannual oscillation in the tropical Pacific. Both theoretical and modeling studies have suggested that ENSO properties such as the growth rate and period depend strongly on the background mean state (e.g., Li and Hogan 1999; Fedorov and Philander 2000; Sun et al. 2009; Chen et al. 2013). Many basic-state fields such as trade wind strength (Guilyardi 2006), zonalmean thermocline depth (Latif et al. 1993), zonal sea surface temperature (SST) gradient (Knutson et al. 1997), and the stability of ocean-atmosphere interaction (Kim and Jin 2011) may modulate the ENSO amplitude. Paleoclimatic data suggest that the abruptly elevated ENSO variability around 14000 years ago may have resulted from the significant retreat of the Laurentide ice sheet, which was basically caused by reduced northsouth cross-equatorial SST contrast in the eastern Pacific (Lu et al. 2016). The suppressed ENSO oscillation during the mid-Holocene $(\sim 6000$ years ago) (compared with the preindustrial situation) may be due to the weakened ocean feedbacks driven by mean surface meridional current changes (Chen et al. 2019). The westerly wind bursts in the western tropical Pacific are important for the development of El Niño event, which is in turn controlled by the mean state of the ocean and oceanatmosphere interaction (e.g., Fedorov et al. 2015). Many studies suggested that the ENSO variability had been strengthening during the past 50 years, which was mainly due to the enhanced thermocline strength (Yang and Zhang 2008; Zhang et al. 2008). Cai et al. (2018) further suggested that the warming-induced intensification of upper-ocean stratification will cause a robust increase in SST variability in the near future under persistent greenhouse gas forcing.

The TP uplift may have affected the ENSO strength through its impact on the mean climate of the tropical atmosphere-ocean system. Many coupled atmosphereocean modeling studies (e.g., Kitoh 1997; Abe et al. 2004; Schmittner et al. 2011; Sinha et al. 2012; Maffre et al. 2017) suggested that the uplift can lead to SST warming in the western tropical Pacific, stronger easterly wind, and thus an enhanced Walker circulation in
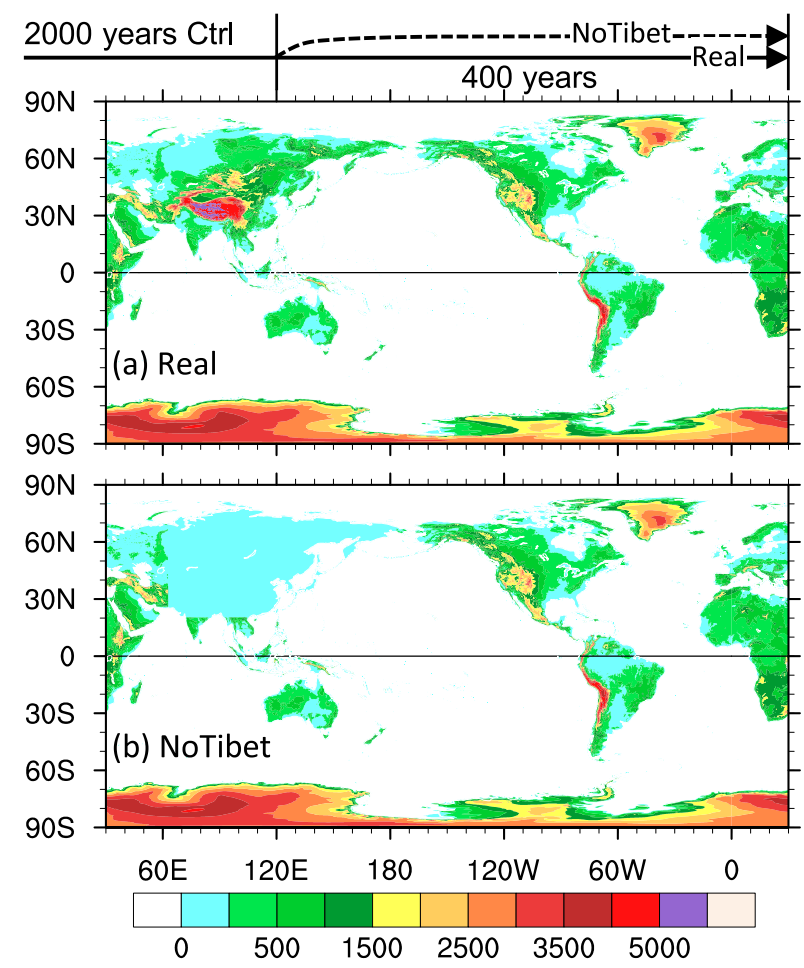

FIG. 1. Topography configuration $(\mathrm{m})$ in coupled model experiments: (a) the control simulation with realistic topography (Real) and (b) the experiment without the Tibetan Plateau (NoTibet). The timeline above (a) shows the integration lengths of these experiments.

the tropical Pacific. Fallah et al. (2016) and Su et al. (2018) showed that the removal of the TP can generate an SST warming in the eastern tropical Pacific, weakened trade winds, and thus an attenuated Walker circulation. These results indicate that the uplift of the TP can exert strong impacts on the tropical oceanatmosphere system. However, the influence of TP uplift on ENSO has not yet been studied thoroughly. A modeling study of Huber and Caballero (2003) suggested that during the Eocene when the TP uplift had not begun, ENSO exhibited a greater amplitude than in the present climate, which is supported by the evidence of ENSO-frequency band variability in Middle Eocene sediments. However, these mechanisms remain unclear because the tectonic movements were complicated during that time (Manabe and Broccoli 1990), and the forcing signals were mixed with large variations in insolation and greenhouse gas concentration (Huber and Caballero 2003; Lowenstein and Demicco 2006). Here, we investigate isolated influences of the TP uplift during the Late Cenozoic on changes in ENSO variability using idealized model simulations.

In this study, a temperature variance equation, proposed by Yang and Zhang (2008), is used to reveal the 
mechanism of ENSO variability change in response to the TP removal. The removal of the TP results in a weaker east-west SST gradient and thus an attenuated Walker circulation in the tropical Pacific, consistent with previous findings (Fallah et al. 2016; Su et al. 2018). The slowdown of the Walker circulation signals a more stable tropical atmosphere (Vecchi and Soden 2007), which tends to weaken the coupled tropical variability. However, the enhanced ENSO variability after removing the TP suggests that the stabilizing factors of the atmospheric process cannot overcome the destabilizing factors of the ocean dynamics (Yang and Zhang 2008). The ocean appears to play a more important role. Thus, it is necessary for us to scrutinize the ocean's roles in changing ENSO intensity. This paper is arranged as follows. In section 2, we briefly introduce the model and experiments. In section 3, we show the changes of tropical climatology and ENSO in topography experiments. In section 4, mechanisms for ENSO intensity change are provided, followed by summary and discussion in section 5 .

\section{Model experiments}

To explore the role of the TP in modulating ENSO properties, two parallel experiments are performed using the Community Earth System Model (CESM1.0) of the National Center for Atmospheric Research (NCAR). The model consists of five components and one coupler: the Community Atmosphere Model (CAM5) (Park et al. 2014), the Community Land Model (CLM4) (Lawrence et al. 2012), the Community Ice Code (CICE4) (Hunke and Lipscomb 2010), the Parallel Ocean Program (POP2) (Smith and Gregory 2009), the Community Ice Sheet Model (Glimmer-CISM), and the CESM Coupler (CPL7). CESM1.0 has been widely used and validated by researchers in the community (http://www2.cesm.ucar.edu/). The model grid employed in this study is T31_gx3v7. The CAM5 has 26 vertical levels, with the finite volume nominally $3.75^{\circ} \times 3.75^{\circ}$ in the horizontal. The CLM4 has the same horizontal resolution as the CAM5. The POP2 has 60 vertical levels, and a uniform $3.6^{\circ}$ spacing in the zonal direction. In the meridional direction, the ocean grid is nonuniformly spaced: It is $0.6^{\circ}$ near the equator, gradually increasing to the maximum $3.4^{\circ}$ at $35^{\circ} \mathrm{N} / \mathrm{S}$ and then decreasing poleward. The CICE4 has the same horizontal grid as the POP2. No flux adjustments are used in CESM1.0.

The experiments include a 2400-yr control run and a 400-yr topography-perturbation run (Fig. 1). The control run uses the preindustrial configuration with $\mathrm{CO}_{2}$ concentration of $285 \mathrm{ppm}$. The model geometry, topography, and continents of the control run are
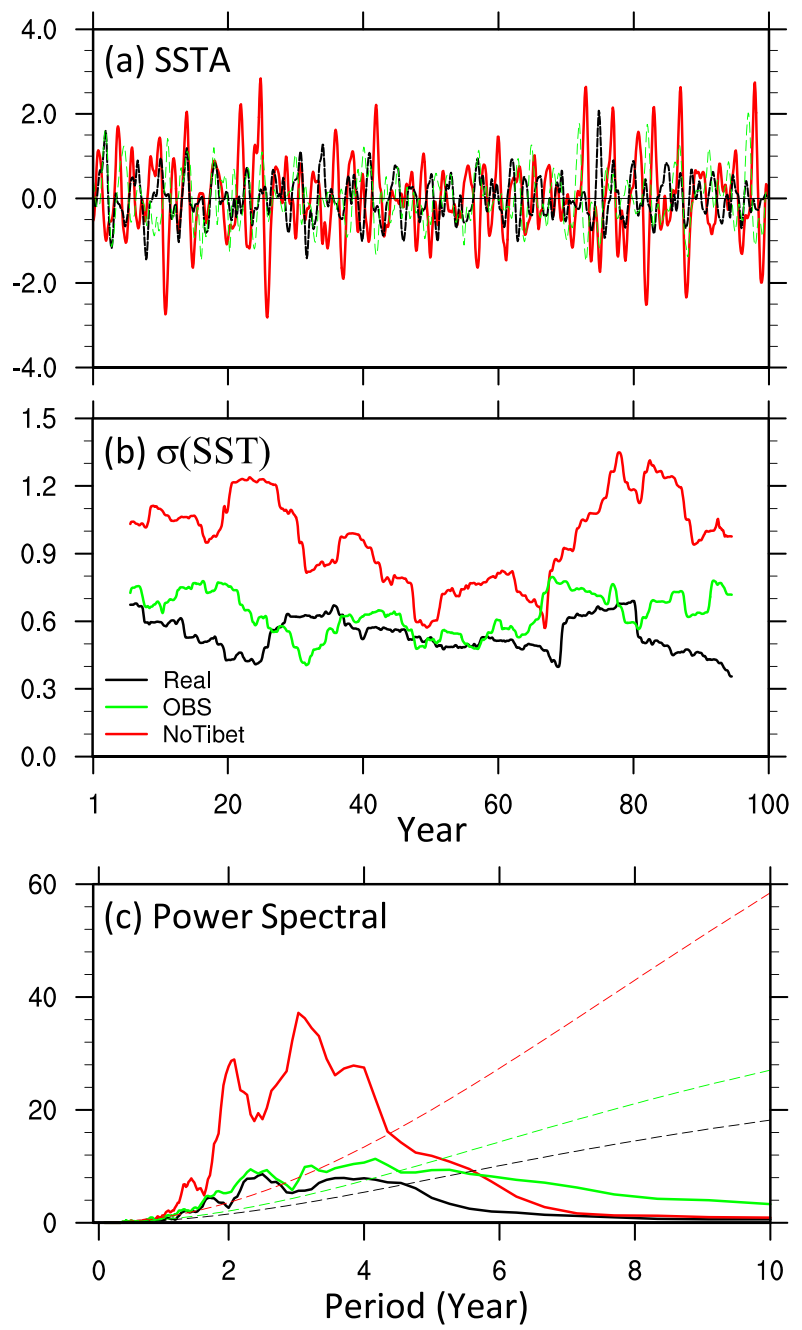

FIG. 2. Time series of SST anomalies (SSTA; ${ }^{\circ} \mathrm{C}$ ), standard deviation of SSTA $\left[\sigma(\mathrm{SST}) ;{ }^{\circ} \mathrm{C}\right]$, and power spectrum of SSTA averaged in the Niño-3 region $\left(5^{\circ} \mathrm{S}-5^{\circ} \mathrm{N}, 150^{\circ}-90^{\circ} \mathrm{W}\right)$. (a) SSTA and (b) $\sigma(\mathrm{SST})$ from Real (black), NoTibet (red), and the ERSST (of 1901-2000; green). The SSTA field is smoothed with a 5-85-month bandpass filter. The $\sigma(\mathrm{SST})$ field is further smoothed with a sliding window of 21 years. (c) The power spectra of the SSTA for Real (black), NoTibet (red), and the ERSST (green), with 95\% confidence levels (dashed lines).

realistic (Fig. 1a). This control run is named "Real." The model climate in Real reaches a quasi-equilibrium state after 1000 years of integration (Yang et al. 2015). The sensitivity experiment without the TP, named "NoTibet," starts from year 2001 of Real, with the topography of the TP reset as $50 \mathrm{~m}$ above the sea level (Fig. 1b), and is integrated for 400 years. Note that the TP area defined in this work is $23^{\circ}-80^{\circ} \mathrm{N}, 63^{\circ} \mathrm{E}-180^{\circ}$. All other boundary conditions in this experiment, such as continent-ocean distributions, planetary albedo, and orbital parameters, are prescribed as in Real. For the regions where the orography is modified, the surface 


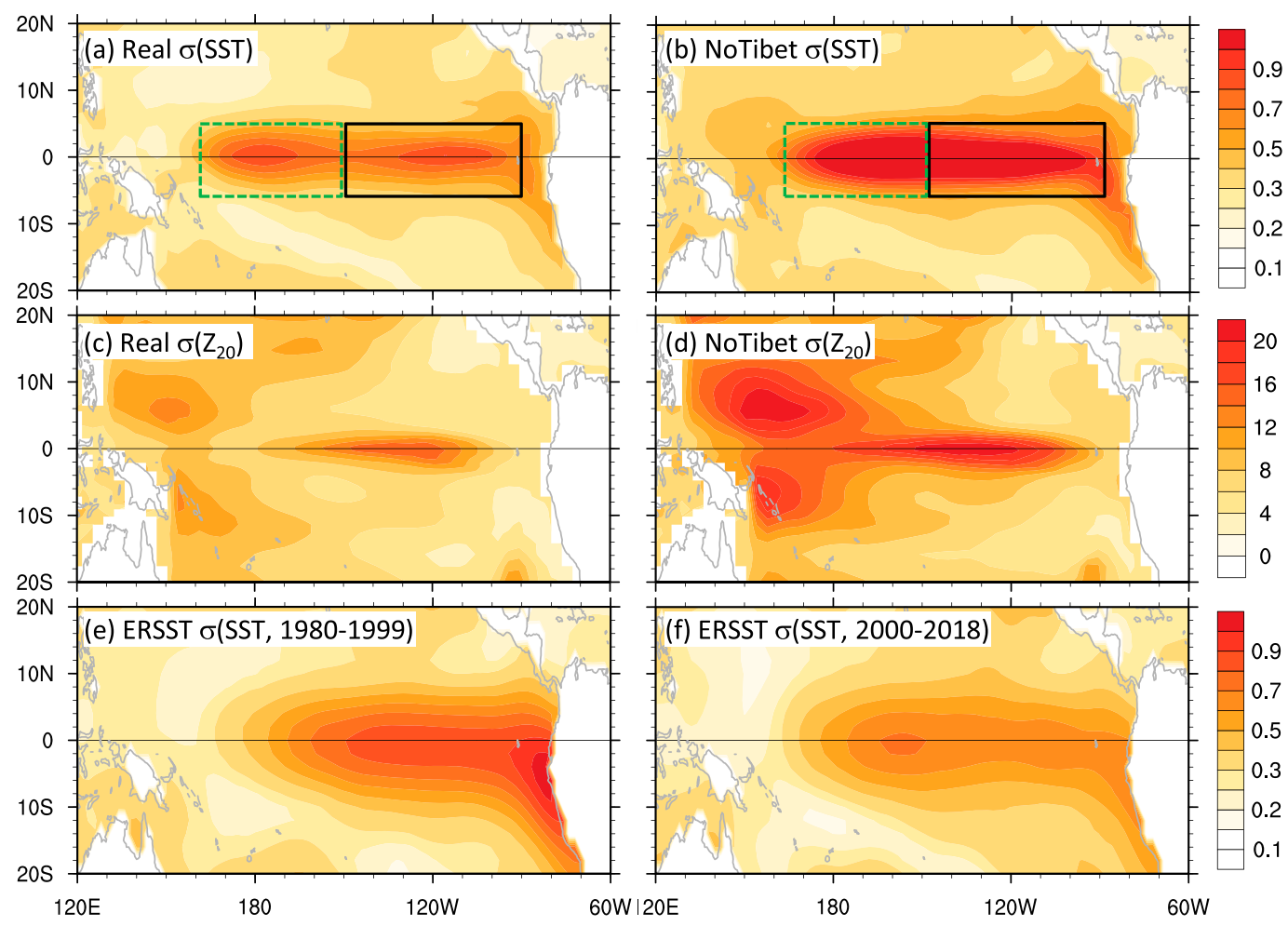

FIG. 3. Spatial patterns of the standard deviations of SSTA $\left({ }^{\circ} \mathrm{C}\right)$ and thermocline depth $(\mathrm{m})$ in the tropical Pacific. (a),(b) SSTs from Real and NoTibet, respectively; (c),(d) thermocline depths from Real and NoTibet, respectively; (e),(f) SSTs from the ERSST during the period of 1980-99 (P1) and of 2000-18 (P2), respectively. The SSTA and thermocline depth are smoothed with a 5-85-month bandpass filter before they are used for calculating standard deviations. P1 and P2 are the two periods to distinguish the eastern El Niño and central El Niño in the tropical Pacific, according to Guan and McPhaden (2016). The thermocline depth $Z_{20}$ is defined by the depth of $20^{\circ} \mathrm{C}$ isotherm. The solid black and dashed green boxes in (a) and (b) outline the Niño-3 $\left(5^{\circ} \mathrm{S}-5^{\circ} \mathrm{N}, 150^{\circ}-90^{\circ} \mathrm{W}\right)$ and Niño$4\left(5^{\circ} \mathrm{S}-5^{\circ} \mathrm{N}, 160^{\circ}-150^{\circ} \mathrm{E}\right)$ regions, respectively.

roughness parameters used in the mountain gravity wave drag parameterization are set to be those over flat land.

The last 100 years of monthly model outputs are used for analyses, during which both the ocean and atmosphere reach quasi-equilibrium states. The quasi-equilibrium responses of variables are obtained by subtracting results of Real from those of NoTibet. The temperature variability discussed in section 4 is obtained as follows. First, the mean seasonal cycle during the last 100 years is removed. Second, a bandpass filter of 5-85 months is applied so that the variability only contains information of interannual time scale.

\section{Equilibrium responses}

\section{a. Change in ENSO amplitude}

Figure 2 shows the time series of ENSO variability with and without the TP. Elevated ENSO variability is clearly seen in the absence of the TP. For comparison, the observations from NOAA Extended Reconstructed SST version 4 (ERSST V4) during 1901-2018 (Huang et al. 2015) are also plotted in Fig. 2. The SST anomaly time series from the ERSST (green line in Fig. 2a) depicts strong 1982/83 and 1997/98 El Niño events. The standard deviation of SST anomaly $[\sigma(\mathrm{SST})]$ in Real is about $0.60^{\circ} \mathrm{C}$ (black curve; Fig. 2b), which is comparable with that from the ERSST (green curve, Fig. 2b). The reasonable agreement of ENSO strength between Real and observation suggests that the CESM model can well reproduce the tropical Pacific variability. In NoTibet, the tropical SST anomaly shows much bigger oscillation, with $\sigma$ (SST) increased to about $1.0^{\circ} \mathrm{C}$ (red curve; Figs. 2a,b). The power spectrum of SST anomalies confirms an enhanced ENSO strength after the TP removal. Note that the principal period is about 2-4 years for both model experiments and observation. The period change in NoTibet is not significant, and we will not elucidate this issue in this study. Note that the curves in 


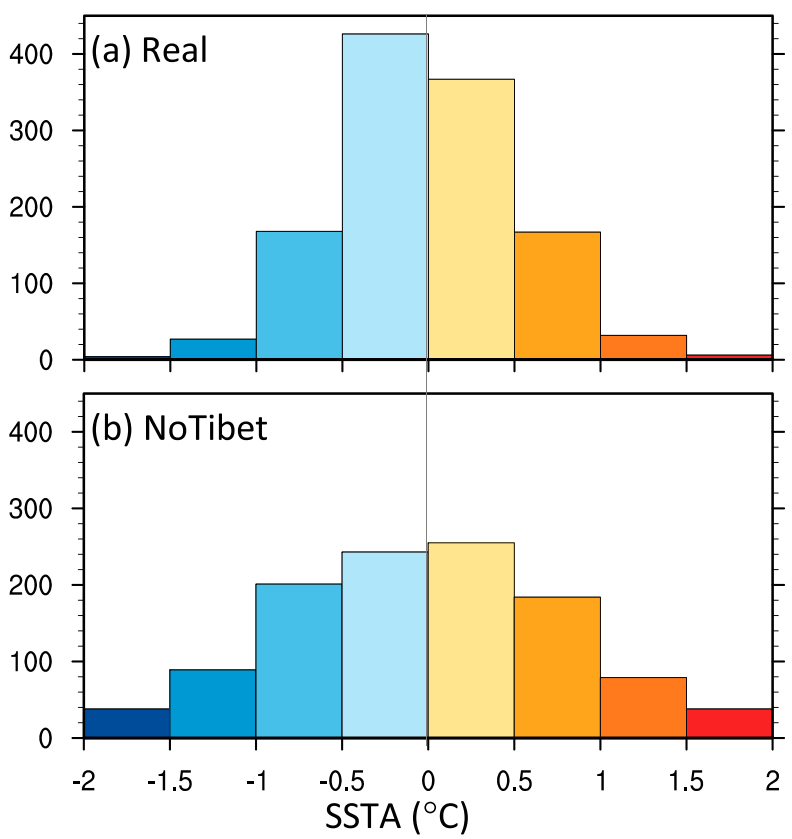

FIG. 4. Distributions of SSTA in Niño-3 region in (a) Real and (b) NoTibet. The SSTA field is smoothed with a 5-85-month bandpass filter.

Fig. 2 are for the SST anomalies in the Niño-3 region $\left(5^{\circ} \mathrm{S}-5^{\circ} \mathrm{N}, 150^{\circ}-90^{\circ} \mathrm{W}\right)$. In the Niño-4 region $\left(5^{\circ} \mathrm{S}-5^{\circ} \mathrm{N}\right.$, $\left.160^{\circ} \mathrm{E}-150^{\circ} \mathrm{W}\right)$, the $\mathrm{SST}$ anomalies show similar features (figure not shown).

The pattern of tropical $\sigma$ (SST) in Real (Fig. 3a) shows two distinguished centers located at $120^{\circ} \mathrm{W}$ and $180^{\circ}$, respectively, which are consistent with the finding of Vega-Westhoff and Sriver (2017). These two centers represent, respectively, the eastern and central Pacific El Niño events (Ashok et al. 2007; Kao and Yu 2009; Lübbecke and McPhaden 2014; Guan and McPhaden 2016), which are also seen in the ERSST data (Figs. 3e,f). In contrast, the SST variability in NoTibet is enhanced in the entire equatorial Pacific (Fig. 3b).

Figures $3 \mathrm{c}$ and $3 \mathrm{~d}$ show thermocline depth variability $\sigma\left(Z_{20}\right)$ in Real and NoTibet, respectively. For the equatorial Pacific, we define the thermocline depth $Z_{20}$ using the depth of $20^{\circ} \mathrm{C}$ isotherm, as in many other studies (e.g., Fedorov and Philander 2001). Unlike $\sigma($ SST), $\sigma\left(Z_{20}\right)$ shows a bigger amplitude in the central-western equatorial Pacific in Real (Fig. 3c). The value of $\sigma\left(Z_{20}\right)$ in NoTibet also shows a notable increase in the whole equatorial Pacific (Fig. 3d). The change of $Z_{20}$ is usually thought to lead the change of SST by about several weeks in the eastern Pacific and by one year in the central Pacific (Zelle et al. 2004), which may be the reason for modulating ENSO amplitude (Rodgers et al. 2004; Zelle et al. 2004). Since the ENSO variability has two centers in Real, we will discuss the mechanisms of ENSO response in the Niño-3 (solid black box) and Niño-4 (dashed green box) regions, separately, in section 4.

Figure 4 shows the histogram of SST anomaly distribution in the Niño-3 region. We can see that the occurrences of El Niño and La Niña events are roughly symmetric in Real (Fig. 4a), and they are nearly symmetrically changed after the TP removal (Fig. 4b). Here, an El Niño or La Niña event is defined by SST anomalies exceeding $\pm 1^{\circ} \mathrm{C}$. More El Niño (La Niña) events occur in NoTibet (Fig. 4b), compared with those in Real; and there is almost no skewness in ENSO variability. The lack of asymmetry of ENSO variability in the model is common in many CMIP3 and CMIP5 models, which is related to many atmospheric and oceanic biases (An and Jin 2004; Sun et al. 2016; Zhang and Sun 2014; Levine et al. 2016; Liang et al. 2017) (see section 5). Our model results suggest that the presence of the TP appears to have no preference for the occurrence of either El Niño or La Niña.

In general, our model results show stronger ENSO variability after the TP removal. As mentioned in the introduction, the ENSO properties are closely related to the background mean climate in the tropical Pacific (e.g., Collins et al. 2010; Cai et al. 2018). To understand the mechanisms of TP-induced ENSO changes, the mean climate change in the tropical Pacific needs to be examined next.

\section{b. Mean climate change}

Removing the TP results in significant warming over the Eurasian continent due to the lapse-rate relationship. The remarkable warming over the Eurasian continent contributes to the weakening of zonal EurasianPacific thermal contrast, leading to the weakening of trade winds and zonal SST gradient in the tropical Pacific (Fig. 5a; also see Su et al. 2018; Wen and Yang 2020; Yang et al. 2020). This suggests a slowdown of the Walker circulation, which is thought to suppress ENSO variability by many studies (e.g., Vecchi and Soden 2007). The SST anomaly pattern shows an El Niño-like response. A further investigation using SST equation indicates that the warmer SST in the central-eastern Pacific is mainly contributed by the anomalous eastward warm water advection, weakened upwelling, increased downward surface shortwave flux, and reduced latent heat flux (figure not shown). These processes can be understood as follows. The weakened trade winds cause anomalous eastward surface ocean currents and weaker equatorial upwelling. The former transports warm water from the western Pacific warm pool, and the latter suppresses subsurface cold water upwelling, both contributing to SST warming in the central-eastern Pacific. At the same time, the weakened easterly winds in the 
(a) SSTA and wind

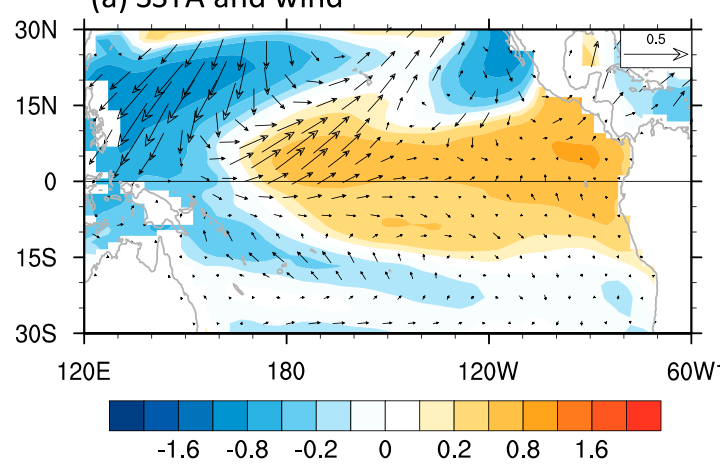

(c) MLD

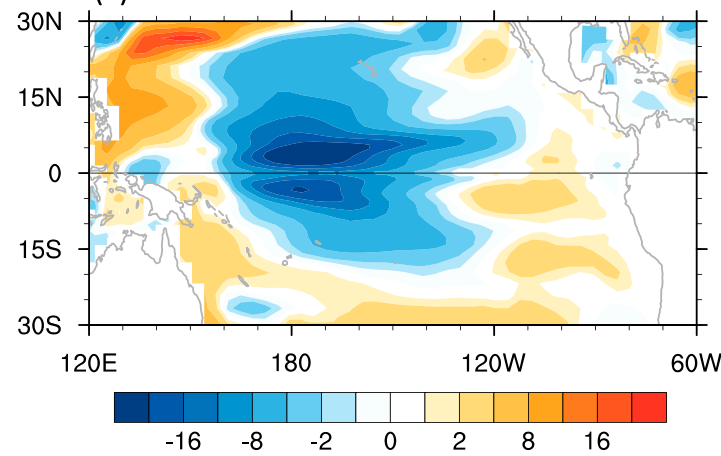

(b) PmE

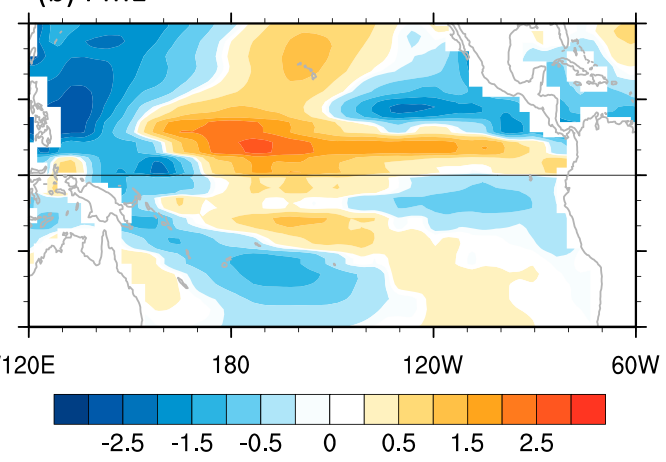

(d) $Z_{20}$

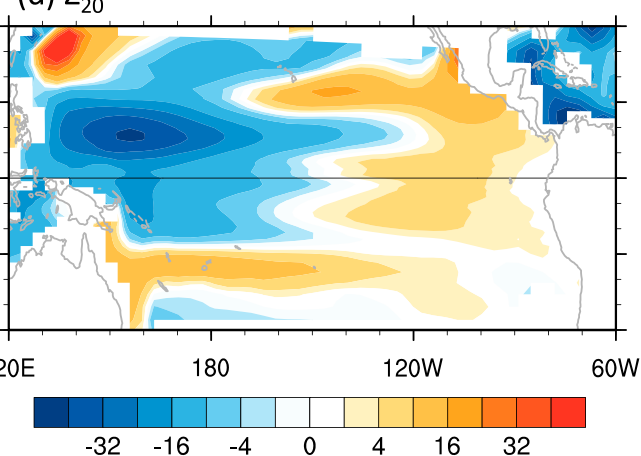

FIG. 5. Quasi-equilibrium changes in mean tropical climate in NoTibet: (a) SST $\left({ }^{\circ} \mathrm{C}\right)$ and surface wind stress $\left(\right.$ dyn $\left.\mathrm{cm}^{-2}\right)$, (b) precipitation minus evaporation $\left(\mathrm{PmE} ; 10^{-5} \mathrm{~kg} \mathrm{~m}^{-2} \mathrm{~s}^{-1}\right.$ ), (c) mixed layer depth $(\mathrm{m})$, and (d) thermocline depth (m).

central-eastern tropical Pacific reduce surface evaporation, which also helps to warm the SST there. The higher SST favors stronger atmospheric convection, leading to less low clouds and thus more downward shortwave radiation, which in turn warms the SST. This process can be also summarized as the low-cloud positive feedback (Zhang and Delworth 2005).

Removing the TP results in moisture convergence, and thus freshwater gain in the central tropical Pacific (Fig. 5b), which reduces the sea surface salinity (SSS) there (figure not shown). The combined effect of lower SSS, higher SST, and weakened trade winds in the central Pacific leads to a shallower mixed layer depth (MLD; Fig. 5c) and thus an intensified stratification in the upper ocean. Previous studies suggested that the strong upper-ocean stratification tends to retard vertical mixing and entrainment of subsurface cold water into the mixed layer, which would favor strong ENSO variability (Carton 1991; Meehl et al. 2001; Kang et al. 2014). Im et al. (2015) also reported that as the MLD decreases, the sensitivity of ocean dynamics to wind forcing becomes larger, which is a primary cause for the increase in positive dynamic feedback and thus a larger El Niño. In this study, the shallower MLD indeed contributes to stronger ENSO variability by enhancing ocean sensitivity to surface wind stress perturbation, a point to be carefully examined in section $4 c$.

Removing the TP also results in flattening equatorial thermocline, with its depth shoaling in the western equatorial Pacific and slightly deepening in the eastern equatorial Pacific (Figs. 5d and 6). Here, the depth of

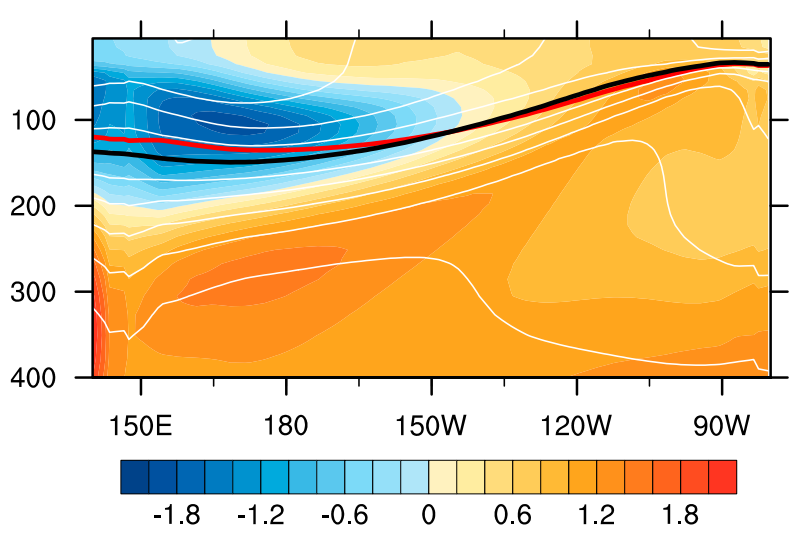

FIG. 6. Upper-ocean temperature $\left({ }^{\circ} \mathrm{C}\right)$ averaged between $5^{\circ} \mathrm{S}$ and $5^{\circ} \mathrm{N}$ in Real (white contours) and its change in NoTibet (shading). The contour interval is $2^{\circ} \mathrm{C}$. The black and red lines represent the mean thermocline depth in Real and NoTibet, respectively, which is defined by the depth of $20^{\circ} \mathrm{C}$ isotherm. 


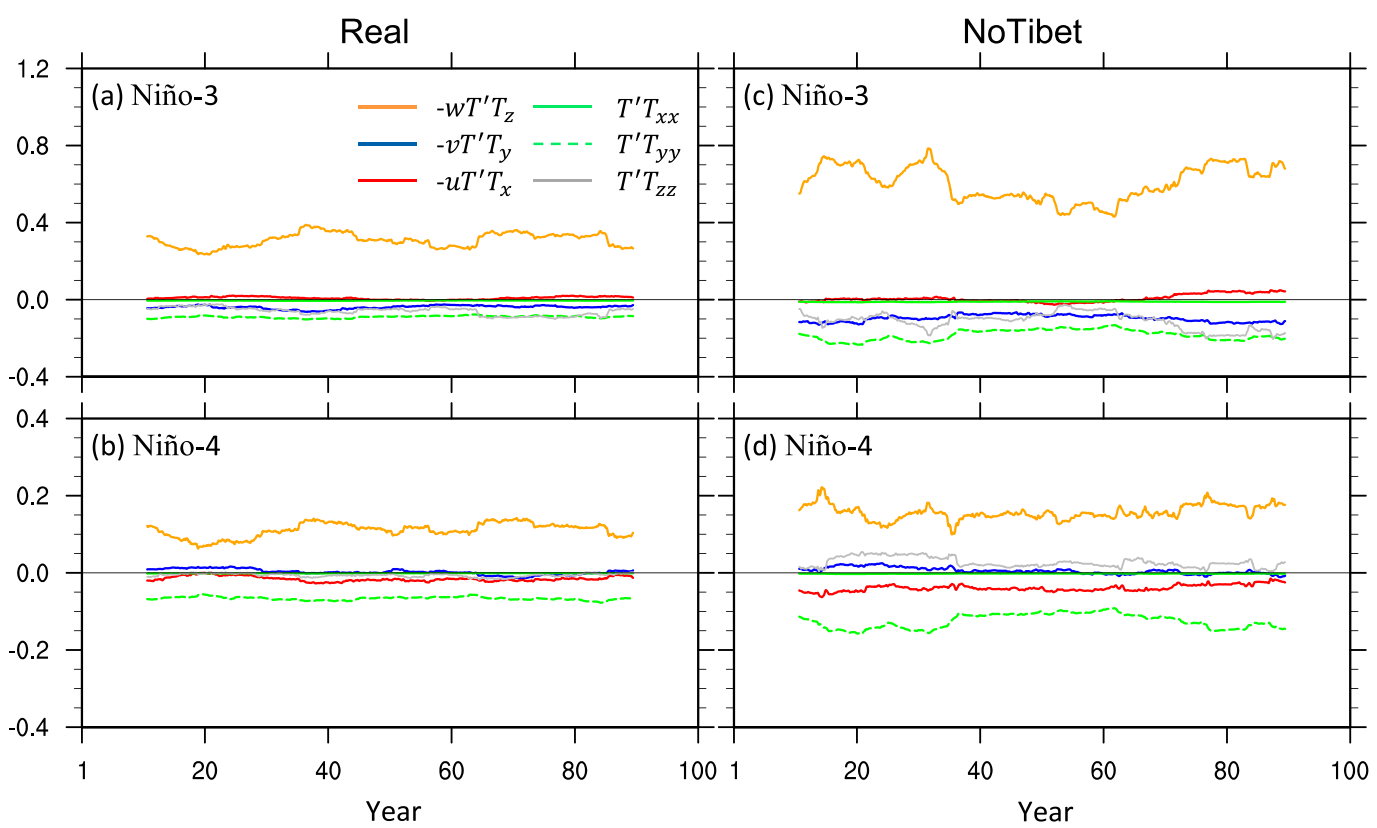

FIG. 7. Time evolution of the terms in the temperature variance equation. (a),(b) The Niño-3 and the Niño-4 regions in Real, respectively. (c),(d) As in (a) and (b), but for NoTibet. A 21-yr sliding window has been applied to each curve. The units of these terms are $10^{-6}{ }^{\circ} \mathrm{C}^{2} \mathrm{~s}^{-1}$.

$20^{\circ} \mathrm{C}$ isotherm $Z_{20}$ is used once again as a proxy for equatorial thermocline depth; thus, the response of thermocline depth is closely related to vertical temperature change. After removing the TP, there is a cooling above $200 \mathrm{~m}$ in the western equatorial Pacific (Fig. 6), which is due to the anomalous ascending motion of the cold water beneath. The upper-ocean warming in the eastern equatorial Pacific is due to suppressed ocean upwelling. Previous studies have established a robust connection between ENSO amplitude and equatorial thermocline. For example, both Zebiak and Cane (1987) and Latif et al. (1993) showed that the amplitude of the El Niño is sensitive to the thermocline depth in the equatorial Pacific. The shallower thermocline in the eastern equatorial Pacific may favor the so-called local mode of SST change, which is important to the strength of ENSO variability (Fedorov and Philander 2001). Philip and van Oldenborgh (2006) suggested that the shoaling of the thermocline, especially in the western equatorial Pacific, is likely to increase SST sensitivity to the thermocline. Other studies, such as Kirtman and Schopf (1998), Barnett et al. (1999), Kleeman et al. (1999), and Fedorov and Philander (2001), all revealed that stronger ENSO variability is associated with deeper thermocline in the eastern equatorial Pacific. In this study, we find that the thermocline slope sensitivity to surface wind stress forcing is increased in the absence of the TP, which plays a destabilizing role in ENSO variability, which will be examined in section $4 \mathrm{c}$.

\section{Mechanisms}

To understand thoroughly the mechanisms of ENSO amplitude change, we diagnose the terms in a temperature variance equation, following the approach used in Yang and Zhang (2008):

$$
\begin{aligned}
\frac{\partial\left[\sigma^{2}(t)\right]}{\partial t}= & \frac{2}{N-1} \sum_{t-N / 2}^{t+N / 2}\left[\left(-\bar{u} T^{\prime} T_{x}^{\prime}-u^{\prime} T^{\prime} \bar{T}_{x}-u^{\prime} T^{\prime} T_{x}^{\prime}\right)\right. \\
& +\left(-\bar{v} T^{\prime} T_{y}^{\prime}-v^{\prime} T^{\prime} T_{y}-v^{\prime} T^{\prime} T_{y}^{\prime}\right) \\
& +\left(-\bar{w} T^{\prime} T_{z}^{\prime}-w^{\prime} T^{\prime} \bar{T}_{z}-w^{\prime} T^{\prime} T_{z}^{\prime}\right) \\
& \left.+A_{h} T^{\prime} T_{x x}^{\prime}+A_{h} T^{\prime} T_{y y}^{\prime}+T^{\prime} Q_{F}^{\prime}+T^{\prime} R_{E}^{\prime}\right]
\end{aligned}
$$

where

$$
\sigma^{2}(t)=\frac{1}{N-1} \sum_{t-N / 2}^{t+N / 2} T^{2}(t) .
$$

Equation (1) denotes the variance of temperature anomaly in a given sliding window. Terms are defined as follows: $N$ is the width of the temporal sliding window, 


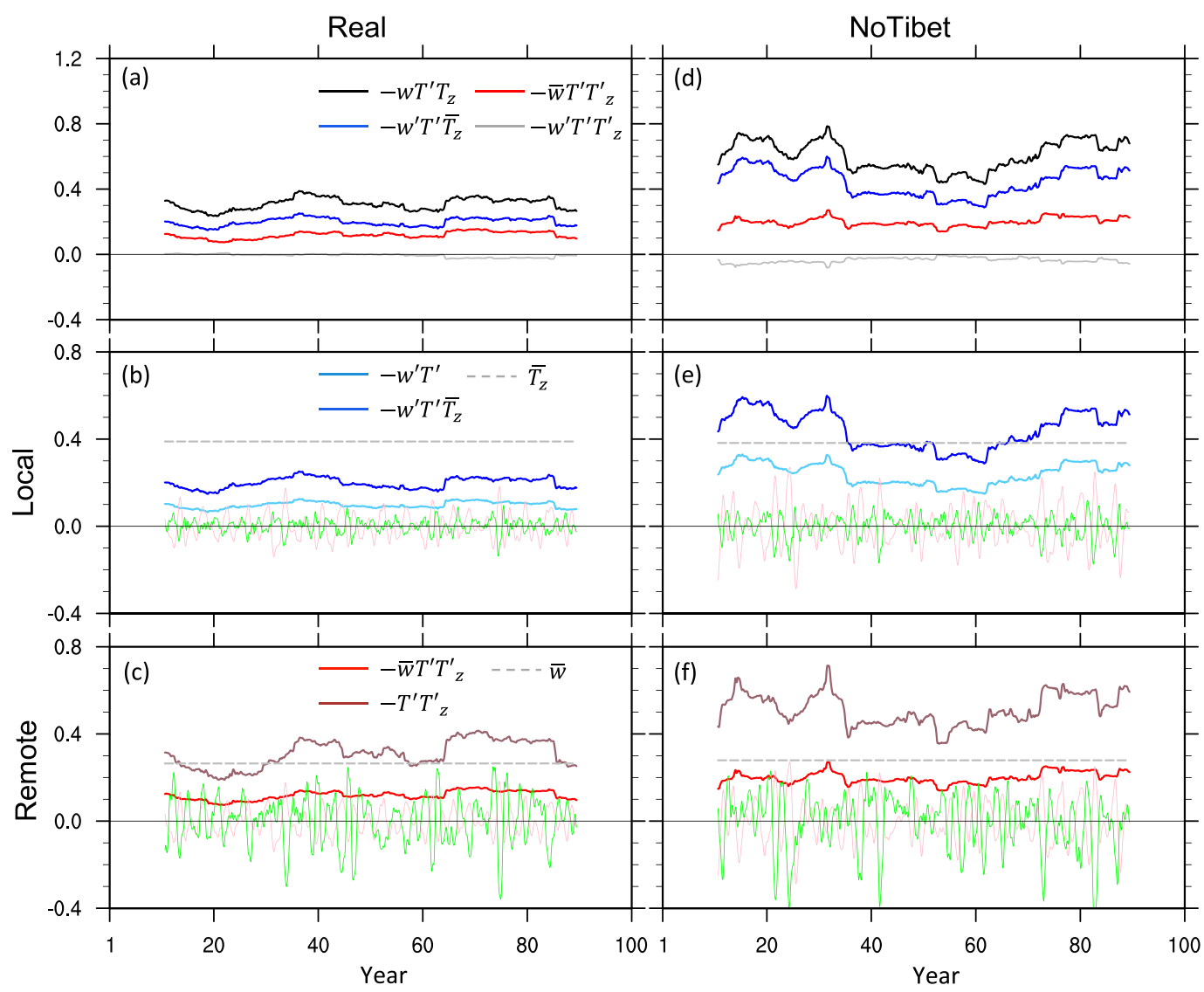

FIG. 8. Decomposition of the vertical temperature advection term averaged in the Niño-3 region over the thermocline for (a)-(c) Real and (d)-(f) NoTibet. In (a) and (d), the black, blue, red, and gray lines represent the total vertical temperature advection $\left(-w T^{\prime} T_{z}\right)$, perturbation upwelling of mean temperature gradient $\left(-w^{\prime} T^{\prime} \overline{T_{z}}\right)$, mean upwelling of perturbation temperature gradient $\left(-\bar{w} T^{\prime} T_{z}^{\prime}\right)$, and pure nonlinear term $\left(-w^{\prime} T^{\prime} T_{z}^{\prime}\right)$, respectively. In (b) and (e), the light blue, blue, and dashed gray curves represent vertical heat flux $\left(-w^{\prime} T^{\prime}\right)$, perturbation upwelling of mean temperature gradient $\left(-w^{\prime} T^{\prime} \overline{T_{z}}\right)$, and mean vertical temperature gradient $\left(\bar{T}_{z}\right)$, respectively. The green and light red curves represent the Ekman pumping anomaly $\left(w^{\prime}\right)$ and temperature anomaly $\left(T^{\prime}\right)$, respectively. In (c) and (f), the dark red, dashed gray, and red curves represent $-T^{\prime} T_{z}^{\prime}$, mean upwelling $(\bar{w})$, and the mean upwelling of perturbation temperature gradient $\left(-\bar{w} T^{\prime} T_{z}^{\prime}\right)$, respectively. The green and light red curves represent vertical gradient of temperature anomaly $\left(T_{z}^{\prime}\right)$ and temperature anomaly $\left(T^{\prime}\right)$, respectively. A $21-\mathrm{yr}$ sliding window has been applied to each term. In (a) and (d), the units are $10^{-6}{ }^{\circ} \mathrm{C}^{2} \mathrm{~s}^{-1}$. In (b), (c), (e), (f), the terms are scaled by a factor of a certain constant so that they can be plotted in the same figure. The units of $w$ and $T_{z}$ are $\mathrm{cm} \mathrm{s}^{-1}$ and ${ }^{\circ} \mathrm{C} \mathrm{cm}^{-1}$, respectively. The values of $\bar{w}, \bar{T}_{z}, w^{\prime} T^{\prime}, T^{\prime} T_{z}^{\prime}, T^{\prime}, T_{z}^{\prime}$, and $w^{\prime}$ are plotted after being multiplied by $2 \times 10^{-3}, 10^{-2}, 10^{-3}, 10^{-3}, 10,10^{-3}$, and $10^{-3}$, respectively.

and is set to 21 years in this study; the overbar denotes annual-mean climatology; $T^{\prime}$ is temperature anomaly, $u^{\prime}, v^{\prime}$, and $w^{\prime}$ are ocean current velocity anomalies, and $T_{x}^{\prime}, T_{y}^{\prime}$, and $T_{z}^{\prime}$ are gradients of temperature anomalies, which are positive eastward, northward, and upward, respectively. Also, $Q^{\prime}$ is the total surface heat flux anomaly, $A_{h}$ is the constant diffusion coefficient $\left(4000 \mathrm{~m}^{2} \mathrm{~s}^{-1}\right)$, and $R_{E}^{\prime}$ includes the vertical diffusion term $A_{v} T^{\prime} T_{z z}^{\prime}$, which is obtained by subtracting the other terms from $\partial \sigma^{2} / \partial t$. The first three terms on the right-hand side of Eq. (1) denote the temperature variance caused by mean ocean current with anomalous temperature gradient $\left(-\bar{u} T^{\prime} T_{x}^{\prime}, \quad-\bar{v} T^{\prime} T_{y}^{\prime}, \quad-\bar{w} T^{\prime} T_{z}^{\prime}\right)$, mean temperature gradient with anomalous ocean currents $\left(-u^{\prime} T^{\prime} \bar{T}_{x},-v^{\prime} T^{\prime} \bar{T}_{y},-w^{\prime} T^{\prime} \bar{T}_{z}\right)$, and anomalous ocean currents with anomalous temperature gradients $\left(-u^{\prime} T^{\prime} T_{x}^{\prime},-v^{\prime} T^{\prime} T_{y}^{\prime},-w^{\prime} T^{\prime} T_{z}^{\prime}\right)$. The fourth and fifth terms represent horizontal mixing. The sixth term is surface heat flux, which always plays a damping role in ENSO variability and is not plotted in Fig. 7. The last term is the residual, which mainly represents vertical temperature diffusion.

The temperature variance equation can be conveniently used to quantify dynamic effects on ENSO 


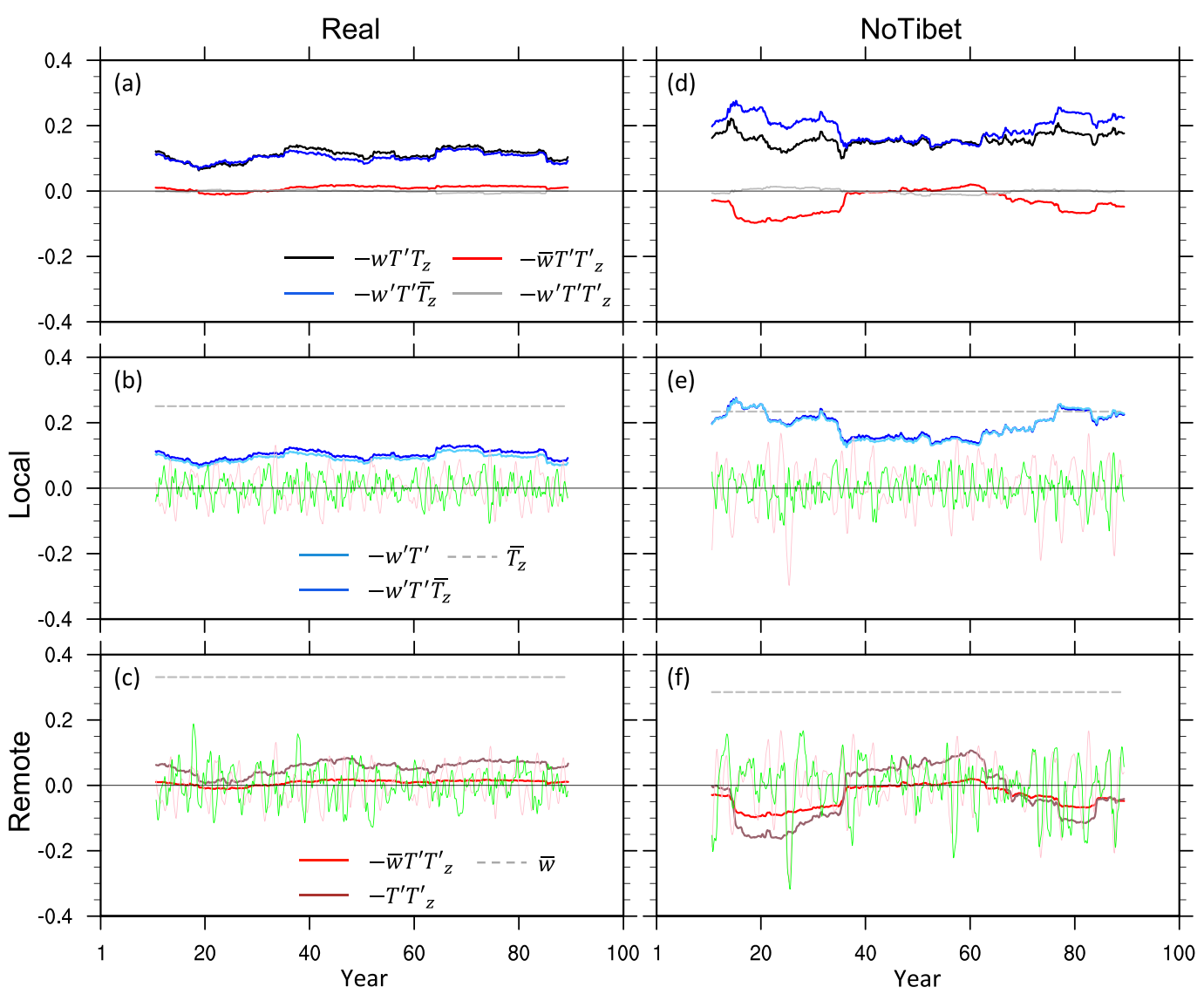

FIG. 9. As in Fig. 8, but for the Niño-4 region.

amplitude, without considering the sign of temperature anomaly (Yang and Zhang 2008; Santoso et al. 2011; Guan and McPhaden 2016). By analyzing these terms, we can identify which term has positive or negative feedback, and thus the underlying mechanism. All terms are calculated within the mean thermocline depth where the term balance analyses can also represent the situation above the thermocline.

\section{a. Destabilizing factors for ENSO variability}

Clearly, the vertical advection term $\left(-w T^{\prime} T_{z}\right)$ is the most important destabilizing factor for temperature variability in both Niño-3 and Niño-4 regions, in both experiments with and without the TP (orange curve; Fig. 7); this is consistent with the conclusion of Yang and Zhang (2008). When the TP is removed, the vertical advection term becomes even stronger, contributing greatly to the enhanced ENSO variability in these two regions (Figs. 7c,d). Note that in the Niño-4 region, the vertical diffusion term $\left(A_{v} T^{\prime} T_{z z}^{\prime}\right)$ also contributes to enhanced ENSO variability after the TP removal (gray curve; Fig. 7d). The positive contribution of vertical diffusion term in the Niño-4 region is due to the stronger upper-ocean stratification mentioned in section $3 \mathrm{~b}$. In the Niño-3 region (Figs. 7a,c), the dominant stabilizing effect comes from the meridional diffusion $\left(A_{h} T^{\prime} T_{y y}^{\prime}\right.$; dashed green curve), meridional advection $\left(-v T^{\prime} T_{y}\right.$; solid blue curve), and vertical diffusion $\left(A_{v} T^{\prime} T_{z z}^{\prime}\right.$; solid gray curve), while in the Niño-4 region (Figs. $7 \mathrm{~b}, \mathrm{~d}$ ) the meridional diffusion $\left(A_{h} T^{\prime} T_{y y}^{\prime}\right.$; dashed green curve) and zonal advection $\left(-u T^{\prime} T_{x}\right.$; red curve) have dominant stabilizing effects. The zonal diffusion term is negligible in these two regions.

Here, we focus on the vertical advection term $\left(-w T^{\prime} T_{z}\right)$, since it is the most important driving mechanism for ENSO variability. This term can be further decomposed into mean upwelling of anomalous vertical temperature gradient $\left(-\bar{w} T^{\prime} T_{z}^{\prime}\right)$, anomalous upwelling of mean vertical temperature gradient $\left(-w^{\prime} T^{\prime} \bar{T}_{z}\right)$, and a higher-order nonlinear term $\left(-w^{\prime} T^{\prime} T_{z}^{\prime}\right)$. The first term can be thought as a remote mode, resulting from the remote wind-thermocline feedback; and it is important in the eastern equatorial Pacific (Fedorov and Philander 2001; Burgers and van Oldenborgh 2003). The second term can be thought of as a local mode, resulting from local SST-wind interaction; it dominates in the central 

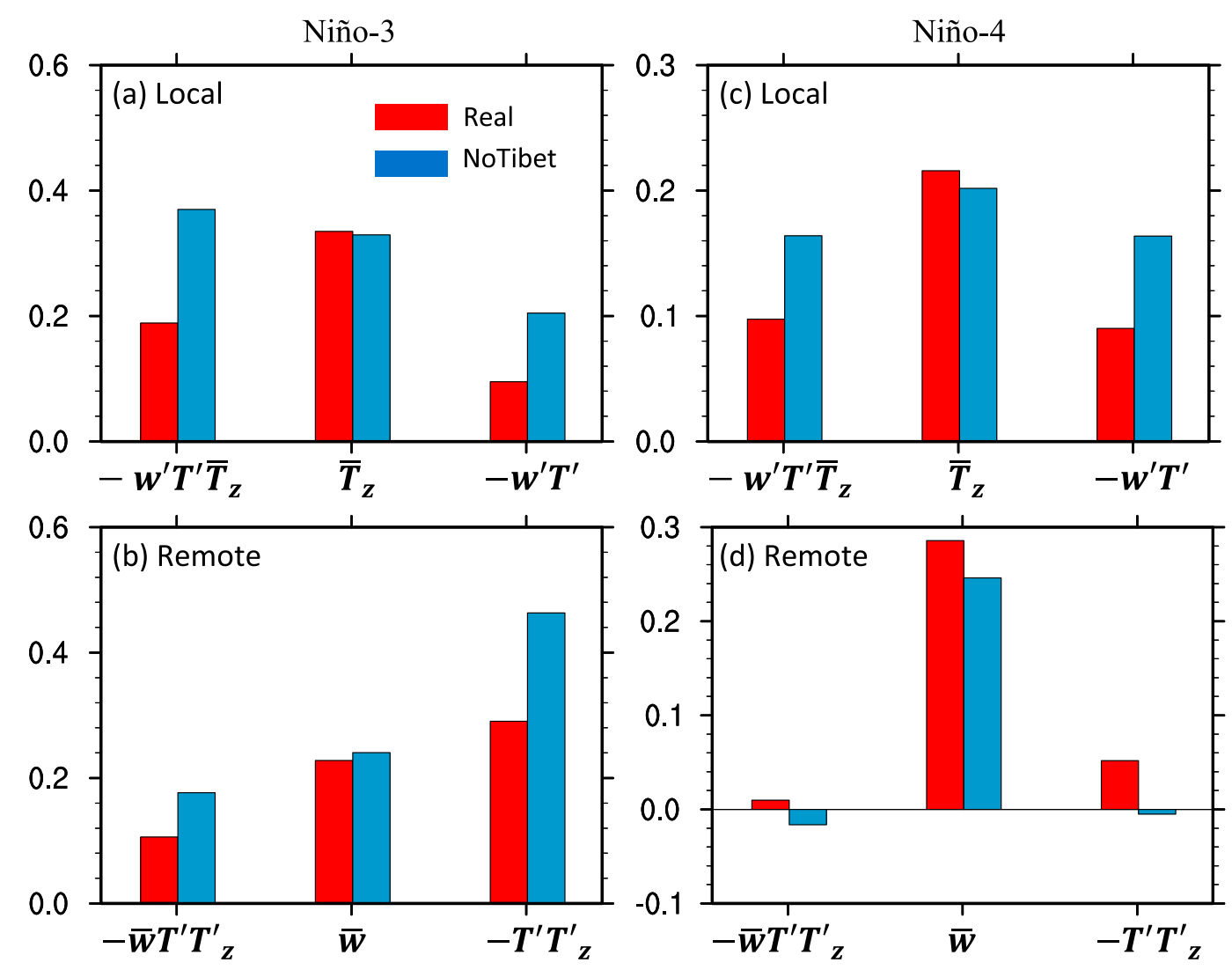

FIG. 10. Bar chart for the mean values of (a) the local term and its components and (b) the remote term and its components averaged in the Niño-3 region over the thermocline. (c),(d) As in (a) and (b), but for the Niño-4 region. The units and scale factors of these terms are as in Fig. 8.

equatorial Pacific (Burgers and van Oldenborgh 2003). These two terms have been recognized widely in terms of ENSO dynamics (Neelin et al. 1998; Wang and McPhaden 2000; Fedorov and Philander 2001; Burgers and van Oldenborgh 2003; Wang and Picaut 2004; Kug and Kang 2006). Note that the higher-order nonlinear term is negligible in this study (solid gray curve; Figs. 8a and 9a).

In the Niño-3 region, both the local mode $\left(-w^{\prime} T^{\prime} \bar{T}_{z}\right)$ and remote mode $\left(-\bar{w} T^{\prime} T_{z}^{\prime}\right)$ play destabilizing roles in ENSO variability, with the former being stronger than the latter (Figs. 8a,d). The local mode is proportional to the mean vertical temperature gradient $\bar{T}_{z}$ and the socalled virtual vertical heat flux $\left(-w^{\prime} T^{\prime}\right.$ ) (Yang and Zhang 2008). Note that $\bar{T}_{z}$ is always positive and also constant in the tropical Pacific, so that the sign and fluctuation of the local mode are determined by $-w^{\prime} T^{\prime}$ (Fig. 8b). Although the temperature anomaly $T^{\prime}$ (pink curve; Fig. 8 b) and vertical velocity anomaly $w^{\prime}$ (green curve; Fig. 8b) oscillate between positive and negative values, their product, after applying a bandpass filter of 5-85 months and a 21-yr sliding window, is always positive. The positive vertical heat flux can be understood as the positive Ekman pumping feedback; that is, an initial positive $T^{\prime}$ reduces the trade wind, which leads to anomalous downwelling $\left(w^{\prime}<0\right)$, and vice versa. This anomalous downwelling can cause surface warming $\left(T^{\prime}>0\right)$, and vice versa. In any case, $-w^{\prime} T^{\prime}>0$ (i.e., an anomalous upwelling or downwelling) always tends to enhance the initial SST perturbation in the Niño-3 region. Later (in Fig. 11b and section 4b), we will see explicitly that upwelling $w^{\prime}$ is determined by Ekman pumping $w_{e}^{\prime}$, which is driven by surface wind stress anomaly. The terms $w^{\prime}$ and $T^{\prime}$ have a strong negative correlation, with the former leading the latter by $2-3$ months, consistent with the finding of Yang and Zhang (2008).

The remote mode $\left(-\bar{w} T^{\prime} T_{z}^{\prime}\right)$ is determined by mean upwelling $\bar{w}$ and $-T^{\prime} T_{z}^{\prime}$; $\bar{w}$ is always positive in the eastern equatorial Pacific because of the climatological Ekman upwelling, so $-T^{\prime} T_{z}^{\prime}$ determines the sign of the remote term (Fig. 8c). We can rewrite it as $-\left(T^{2} / 2\right)_{z}$, representing the vertical gradient of temperature variability. The positive $-T^{\prime} T_{z}^{\prime}$ can be understood as 
positive thermocline feedback; that is, an initial positive $T^{\prime}$ in the eastern tropical Pacific reduces the basinwide trade wind and thus leads to a flattened thermocline, which induces a warmer subsurface water and vertical temperature gradient reduction $\left(T_{z}^{\prime}<0\right)$. The anomalous warmer subsurface water is transported upward by mean upwelling, amplifying the initial positive $T^{\prime}$ and thus playing a destabilizing role in ENSO variability $\left(-T^{\prime} T_{z}^{\prime}>0\right)$. Thus, this term describes the effect of changes in the equatorial thermocline slope forced by anomalous basinwide zonal wind stress on subsurface temperature, and subsequently via mean upwelling. The importance of the thermocline feedback is emphasized in the concept of the delayed oscillator (Battisti and Hirst 1989) and of the recharge oscillator (Jin 1997).

In the Niño-4 region, only the local mode plays an important destabilizing role in ENSO variability, while the contribution of the remote mode is negligible (Fig. 9a). This is understandable because the thermocline depth in the central-western Pacific is much deeper than that in the eastern Pacific, so the interaction between SST and thermocline is weak in the west. This is also consistent with previous findings (Zelle et al. 2004; Yang and Zhang 2008). Later (in Figs. 11a and 11c and section $4 \mathrm{~b}$ ) we will see explicitly that the remote term is well correlated to temperature variability in the Niño-3 region, with the former leading the latter by 2-3 months, whereas in the Niño- 4 region the correlation between these two variables is insignificant.

\section{b. Changes in term balance after removing the TP}

It has been shown in Figs. 8 and 9 that the destabilizing effect of vertical temperature advection is enhanced substantially when the TP is removed. Specifically, in the Niño-3 region both the local term $\left(-w^{\prime} T^{\prime} \bar{T}_{z}\right)$ and remote term $\left(-\bar{w} T^{\prime} T_{z}^{\prime}\right)$, that is, the Ekman upwelling feedback and thermocline feedback, contribute to the enhanced ENSO variability (Figs. 8d-f); in the Niño-4 region, only the local term contributes to the enhanced temperature variability (Figs. 9d-f).

A summary of the destabilizing effect and its change is shown in Fig. 10. For the Niño-3 region, the effect of the local term is enhanced by about $100 \%$, which is mainly contributed by the enhanced vertical heat flux $\left(-w^{\prime} T^{\prime}\right)$ (increased by $125 \%$; Fig. 10a), in response to the TP removal. The mean vertical temperature gradient is roughly unchanged. Removing the TP also results in about $70 \%$ increase in the effect of the remote term (Fig. 10b), which is mainly controlled by increased gradient of temperature variability $\left(-T^{\prime} T_{z}^{\prime}\right)$ (about $\left.60 \%\right)$. The change in mean upwelling is negligible. For the Niño-4 region, the enhanced temperature variability comes only from the enhanced local term, whose effect is increased by about $70 \%$ (Fig. 10c). The enhanced local term effect can be explained solely by the vertical heat flux (increased by $80 \%$ ). The remote mode in the Niño-4 region is negligible (Fig. 10d).

The roles of the local and remote modes in ENSO variability can also be inferred from correlation analyses (Fig. 11). In the Niño-3 region, the local term leads the temperature variability by about 2 months, with the peak correlation of about 0.6 (blue curve; Fig. 11a). This is mainly due to the vertical heat flux effect (light blue curve). The remote term leads the temperature variability by about 3 months, with the peak correlation of about 0.7 (red curve), which can be attributed to the effect of $-T^{\prime} T_{z}^{\prime}$ (dark red curve). The effect of the local term in the Niño-4 region is similar to that in the Niño-3 region (blue and light blue curves, Fig. 11c), while the correlation between the remote term and temperature variability is small and insignificant (red and dark red curves). For both regions, the change in local Ekman upwelling leads the change in local temperature by 2-3 months, with the peak correlation of about 0.8 (black and gray curves; Figs. 11b,d). Figure 11 shows the situation in Real. The situation in NoTibet is very similar to that in Real (figure not shown).

In general, the mechanisms for surface ocean variability in the Niño-3 and Niño-4 regions are different. In the Niño-3 region, both the thermocline and Ekman pumping feedbacks are responsible for ENSO variability. In the Niño-4 region, only the Ekman pumping feedback is important. Removing the TP results in stronger thermocline and Ekman pumping feedbacks, and thus stronger ENSO variability. Next, we will further examine these two feedbacks by investigating changes in tropical ocean sensitivities.

\section{c. Changes in tropical ocean sensitivity}

Many studies have concluded that a strengthening thermocline can lead to stronger ENSO variability (e.g., Timmermann et al. 1999; Meehl et al. 2001). However, we would like to emphasize that our model results suggest that the increased vertical heat flux $\left(-w^{\prime} T^{\prime}\right)$ is the primary reason for the stronger ENSO variability in NoTibet (Figs. 8a,b,d,e), while the thermocline process $\left(-T^{\prime} T_{z}^{\prime}\right)$ is the secondary reason (Figs. 8a,c,d,f). Given a temperature anomaly $T^{\prime}$, the enhanced vertical heat flux comes from enhanced $-w^{\prime}$, while the enhanced thermocline process comes from increased $-T_{z}^{\prime}$. Here, we rewrite $-w^{\prime}$ and $-T_{z}^{\prime}$ in a form of sensitivity to initial temperature perturbation $T^{\prime}$ following Jin et al. (2006) and Liu et al. (2014) with some modifications; then, these two processes are determined by sensitivity coefficients. The anomalous zonal wind stress $\left(\tau_{x}^{\prime}\right)$ sensitivity to the eastern Pacific temperature anomaly $T^{\prime}$ (here 

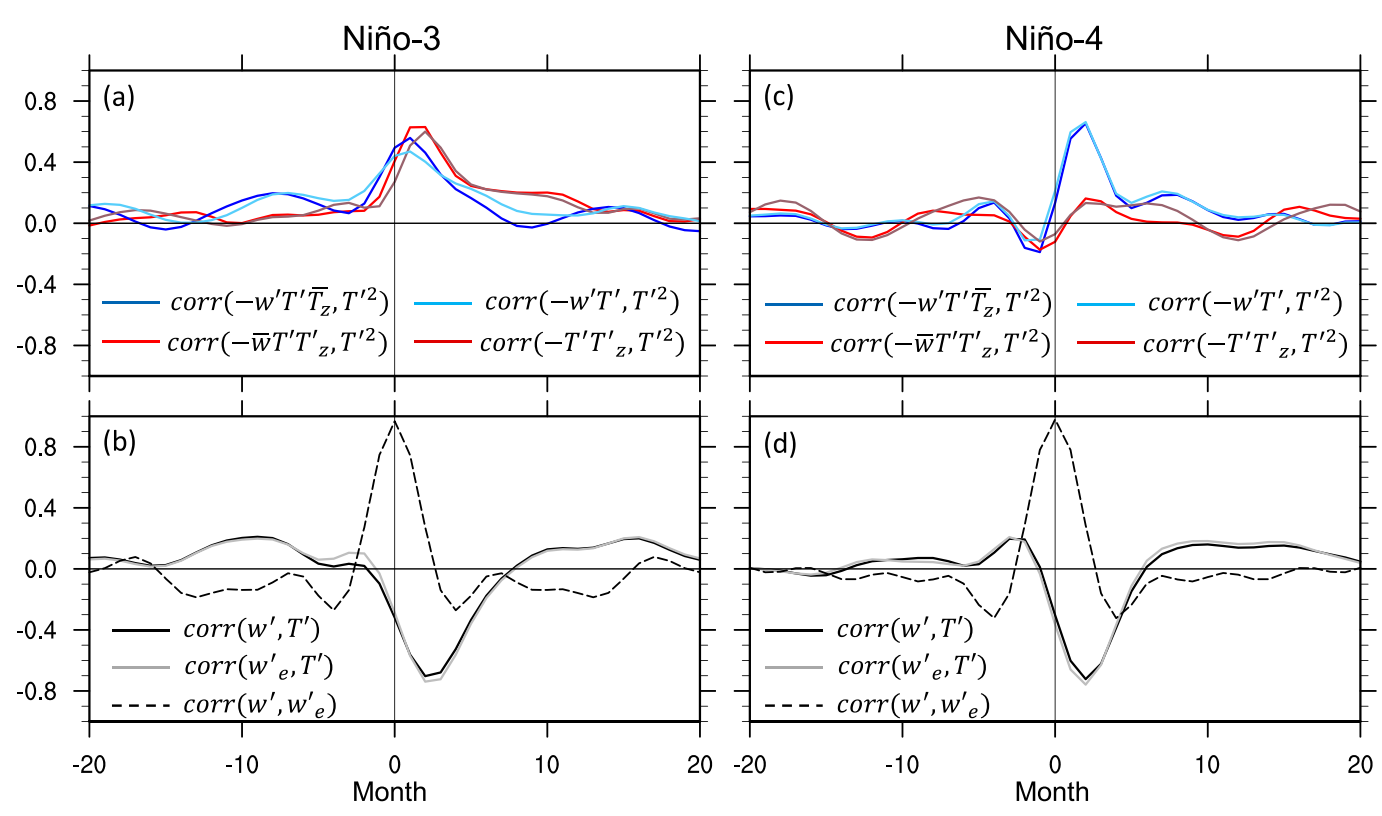

FIG. 11. (a) Lagged correlations between temperature variability and the local term (blue), between temperature variability and vertical heat flux (light sky blue), and between the vertical remote term (red) and $-T^{\prime} T_{z}^{\prime}$ (dark red) in the Niño-3 region in Real. Positive monthly mean temperature variability lags the other terms. (b) Lagged correlations among anomalous temperature $\left(T^{\prime}\right)$, upwelling $\left(w^{\prime}\right)$, and Ekman pumping $\left(w_{e}^{\prime}\right)$ over the thermocline in the Niño-3 region in Real. The black, gray, and dashed black curves represent the correlations between $w^{\prime}$ and $T^{\prime}$, between $w_{e}^{\prime}$ and $T^{\prime}$, and between $w^{\prime}$ and $w_{e}^{\prime}$, respectively. Positive month means the time that $T^{\prime}$ lags $w^{\prime}, T^{\prime} \operatorname{lags} w_{e}^{\prime}$, or $w_{e}^{\prime}$ lags $w^{\prime}$, respectively. (c),(d) As in (a) and (b), but for the Niño-4 region.

referring to the Niño-3 index) is estimated approximately as the regression coefficient $\mu_{a}$ :

$$
\tau_{x}^{\prime}=\mu_{a} T^{\prime}
$$

The anomalous Ekman upwelling $\left(w^{\prime}\right)$ sensitivity to the wind stress perturbation averaged over the tropical Pacific $\left(5^{\circ} \mathrm{S}-5^{\circ} \mathrm{N}, 140^{\circ} \mathrm{E}-90^{\circ} \mathrm{W}\right)$ is regressed as follows:

$$
w^{\prime}=-\beta_{w} \tau_{x}^{\prime}
$$

So, we have

$$
-w^{\prime}=\beta_{w} \mu_{a} T^{\prime}
$$

Also,

$$
-T_{z}^{\prime}=\frac{T_{\mathrm{sub}}^{\prime}}{H}
$$

where $T_{\text {sub }}^{\prime}$ denotes subsurface ocean temperature anomalies induced by vertical thermocline movement; and $H$ is the climatology thermocline depth, which becomes deeper in the eastern tropical Pacific in the absence of the TP (red curve; Fig. 6). The entrainment temperature in the eastern Pacific is proportional to the depth of local thermocline or the upper-ocean heat content $h^{\prime}$ averaged over the eastern Pacific $\left(5^{\circ} \mathrm{S}-5^{\circ} \mathrm{N}\right.$, $\left.170^{\circ}-120^{\circ} \mathrm{W}\right)$ :

$$
T_{\text {sub }}^{\prime}=a h^{\prime}
$$

The thermocline slope sensitivity to wind stress is regressed as follows:

$$
h^{\prime}-\left[h^{\prime}\right]=\beta_{h} \tau_{x}^{\prime},
$$

where $[\cdots]$ stands for zonally averaged value over the tropical Pacific. Finally,

$$
-T_{z}^{\prime}=\frac{a \beta_{h}\left[\tau_{x}^{\prime}\right]}{H}=\frac{a \beta_{h} \mu_{a} T^{\prime}}{H} .
$$

The bigger $H$ favors suppressed $-T_{z}^{\prime}$ and $a=1$ in a comprehensive model (Jin et al. 2006). The enhanced $-w^{\prime}$ and $-T_{z}^{\prime}$ come from zonal wind stress sensitivity $\left(\mu_{a}\right)$ and oceanic response sensitivity $\left(\beta_{w}\right.$ and $\left.\beta_{h}\right)$, respectively. These sensitivities can be easily quantified using model outputs.

Figure 12 shows the spatial patterns of wind stress sensitivity $\mu_{a}$ and Ekman pumping sensitivity $\beta_{w}$. Positive $\mu_{a}$ means a westerly (easterly) wind anomaly in response to a warm (cold) anomaly in the Niño-3 region. In Real, 

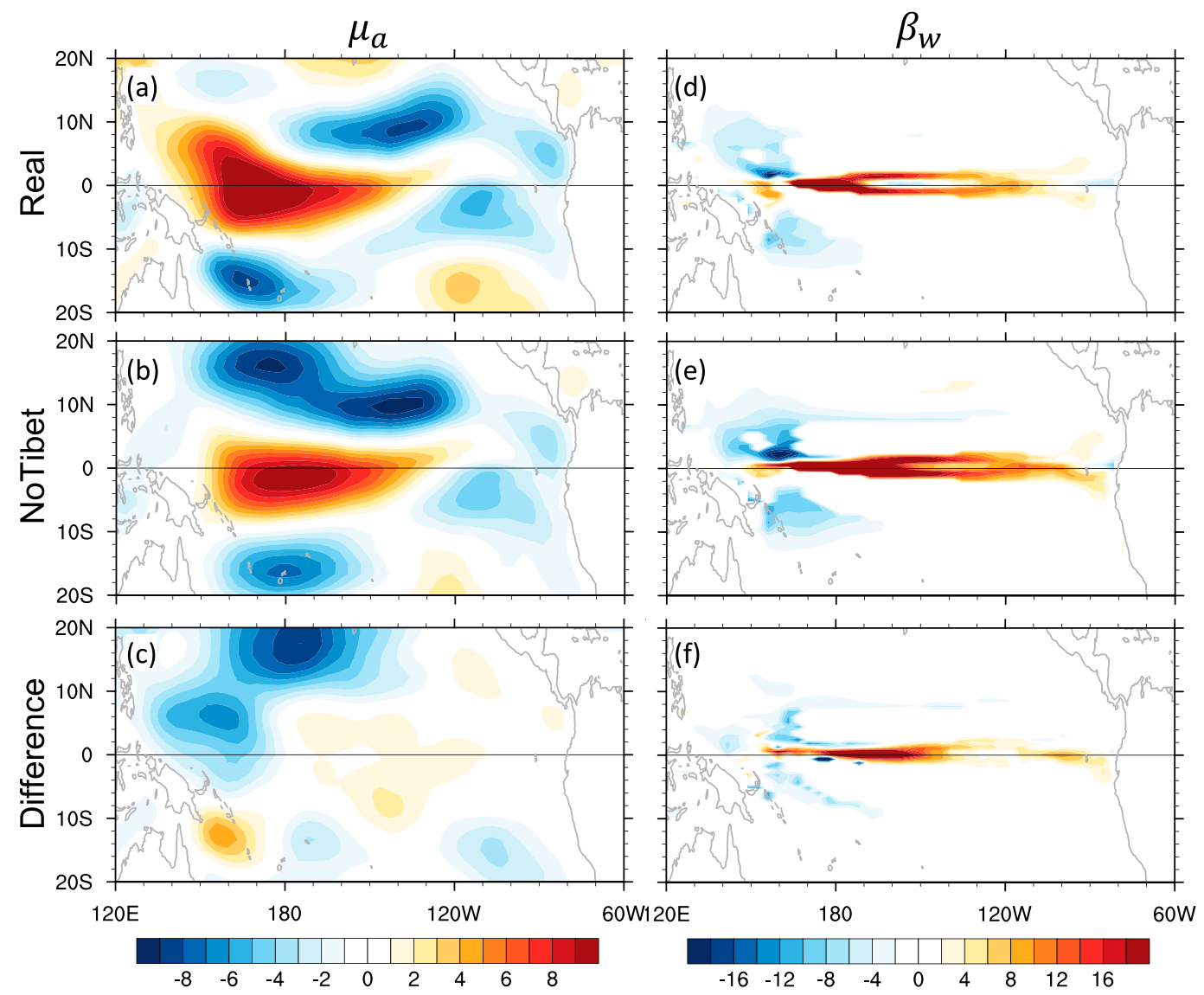

FIG. 12. Spatial patterns of regression coefficients between surface wind stress anomalies and the Niño-3 SSTA $\left(\mu_{a} ; 10^{-3} \mathrm{~N} \mathrm{~m}^{-2}{ }^{\circ} \mathrm{C}^{-1}\right)$ in (a) Real, (b) NoTibet, and (c) their differences. (d)-(f) As in (a)-(c), but for the regression coefficient between anomalous upwelling velocity averaged at thermocline depth and surface wind stress anomalies averaged over the tropical Pacific $\left(5^{\circ} \mathrm{S}-5^{\circ} \mathrm{N}, 140^{\circ} \mathrm{E}-90^{\circ} \mathrm{W}\right)\left(\beta_{w} ; 10^{-5} \mathrm{~m} \mathrm{~s}^{-1} \mathrm{~N}^{-1} \mathrm{~m}^{-2}\right)$.

positive $\mu_{a}$ occurs mainly in the central-western Pacific (Fig. 12a) where downwelling Kelvin waves are generated (Capotondi et al. 2006; Naiman et al. 2017). Removing the TP results in an eastward shift of this positive wind stress sensitivity (Fig. 12b), suggesting an eastward shift of atmospheric convection center. This relationship between wind stress sensitivity and atmospheric convection center has been reported in previous studies (Guilyardi et al. 2009a; Kim and Jin 2011; Lübbecke and McPhaden 2014). The eastward shift of wind stress sensitivity results in bigger $\mu_{a}$ in the central-eastern equatorial Pacific (Fig. 12c), and thus bigger $-w^{\prime}$ and $-T_{z}^{\prime}$ based on Eqs. (5) and (9). The positive $\beta_{w}$ in Real (Fig. 12d) means a downwelling (upwelling) anomaly in response to a westerly (easterly) wind anomaly. Removing the TP also results in bigger $\beta_{w}$ in the whole equatorial Pacific (Fig. 12f) and thus bigger $-w^{\prime}$ as well, because of the shoaling of MLD (Fig. 5c), as mentioned in section 3b (Philip and Van Oldenborgh 2006; Kim and Jin 2011). The increased $-T_{z}^{\prime}$ in the eastern Pacific also comes from a bigger $\beta_{h}$ in the absence of the TP (Fig. 13). Kim et al. (2014) revealed that the strength of $\beta_{h}$ varies with climatological zonal thermocline slope, which increases as the thermocline slope flattens, but decreases thereafter as the thermocline slope steepens, which is confirmed in this study. In addition, the eastward movement of wind stress sensitivity to temperature anomaly after the TP removal can explain the strengthening $\beta_{h}$. Clarke et al. (2007) and Lübbecke and McPhaden (2014) suggested that as ENSO-related wind anomalies are stronger and more confined to the eastern basin, the thermocline slope response to wind stress anomaly becomes stronger.

In general, removing the TP results in stronger Ekman feedback and thermocline feedback, contributing to the elevated ENSO variability. The change in ENSO variability in response to the TP removal is closely related to changes in background conditions in the tropical Pacific, including the location and intensity of the trade wind, thermocline depth, and upper-ocean stratification. 


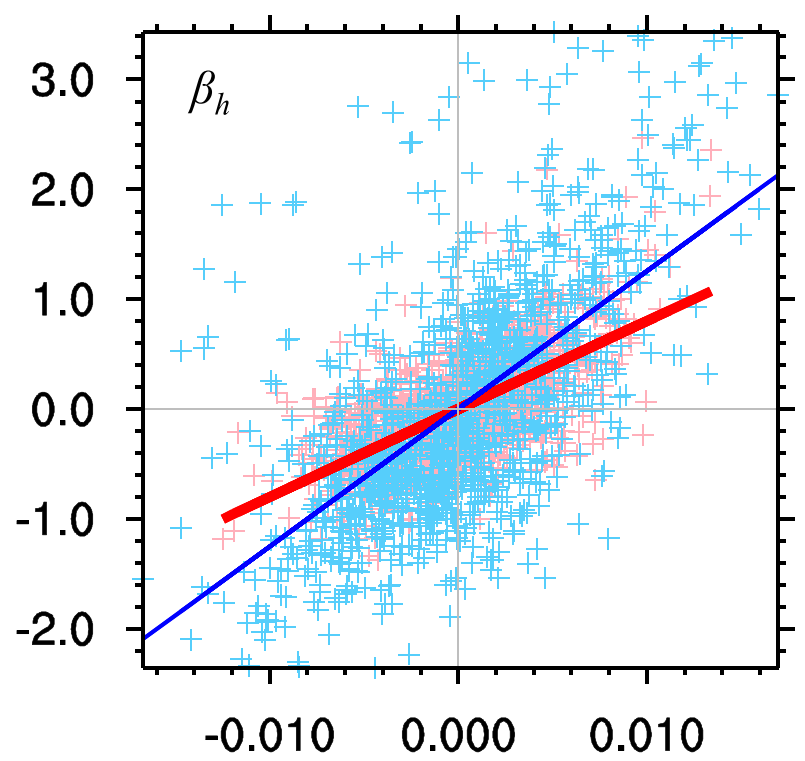

FIG. 13. Scatterplots for the thermocline slope [difference in upper-ocean heat content anomalies $\left({ }^{\circ} \mathrm{C} ; y\right.$ axis $)$ in the eastern Pacific $\left(5^{\circ} \mathrm{S}-5^{\circ} \mathrm{N}, 170^{\circ}-120^{\circ} \mathrm{W},\right)$ and western Pacific $\left(5^{\circ} \mathrm{S}-5^{\circ} \mathrm{N}\right.$, $\left.120^{\circ} \mathrm{E}-180^{\circ}\right)$ ] vs basinwide equatorial zonal wind stress anomalies $\left(5^{\circ} \mathrm{S}-5^{\circ} \mathrm{N}, 140^{\circ} \mathrm{E}-90^{\circ} \mathrm{W} ; \mathrm{N} \mathrm{m}^{-2} ; x\right.$ axis $)$. The red line is the linear regression line of the pink scattered crosses for Real, the slope of which refers to the thermocline slope response to anomalous zonal wind stress forcing $\left(\beta_{h}\right)$. The blue line is the same as the red line, but is for NoTibet.

\section{Summary and discussion}

In this study we investigate the role of the TP in ENSO variability using a fully coupled climate model. The ENSO exhibits an enhanced variability after the TP removal. Removing the TP results in a weakened trade wind and flattened thermocline in the equatorial Pacific. The weakened trade wind leads to an El Niño-like SST response in the tropical Pacific, which causes an eastward shift of atmospheric convection center and shallower MLD in the central-eastern Pacific. Analyses of the temperature variance equation reveal distinct dynamic mechanisms behind the elevated ENSO variability in the Niño-3 and Niño-4 regions. In the Niño-3 region, both the enhanced thermocline and Ekman upwelling positive feedbacks are responsible for the enhanced ENSO variability, while in the Niño-4 region the elevated ENSO variability is only caused by the enhanced positive Ekman upwelling feedback. The changes of these two feedbacks are attributed to the eastward shift of atmospheric convection center and enhanced ocean sensitivities. The enhanced ocean sensitivities are related to a shallower mixed layer. In addition, the thermocline feedback is contributed by the flattened equatorial thermocline after the TP removal.
This study highlights the ocean's role, and suggests that the TP may play a critical role in suppressing ENSO variability.

Both observations and climate models show that in the Eocene (55-35 Ma), ENSO exhibited a greater amplitude than it is today (Huber and Caballero 2003) before the large-scale uplift of mountains (Manabe and Broccoli 1990). This scenario is qualitatively supported by our modeling study; that is, the ENSO variability shows a stronger amplitude after removing the TP, compared with the modern conditions. Although it is a highly idealized modeling study, our results may provide a reference for understanding the evolution process of the Cenozoic ENSO during which the TP experienced a significant phase uplift (Manabe and Broccoli 1990).

In this study, we use the temperature variance equation to quantify ocean dynamics in ENSO amplitude change, and focus on the vertical advection term. This analysis is different from that used in previous works. For example, Feng and Poulsen (2014), Kitoh (2007), and Naiman et al. (2017) studied the effects of global or regional orography on ENSO variability, but their analyses were more or less qualitative. Bear in mind that although the mean state change over the equatorial Pacific is similar to an Indonesian Throughflow (ITF) closure experiment in Santoso et al. (2011), like the weakened trade wind and a flattened equatorial thermocline, the ENSO variability may still have different responses. Changes in atmospheric convection scheme and ocean MLD are also important factors contributing to the properties of ENSO variability. As was done in many previous studies (Fedorov and Philander 2000; An and Jin 2004), we have examined the impact of background mean state induced by the removal of TP over tropical Pacific on the ENSO activity. However, the ENSO activity may also feed back to the mean climate (Sun and Zhang 2006) and the mean climate already has the rectified ENSO effect (Liang et al. 2012; Ogata et al. 2013; Sun et al. 2014; Penland and Sardeshmukh 1995). Note that the stability of the mean climate of the coupled tropical ocean-atmosphere system is not the same as the stability of the equilibrium states of the coupled tropical ocean-atmosphere system (Sun 1997; Liang et al. 2012; Hua et al. 2018). So, we should be cautious when using the stability of the mean climate as a predictor of the level of ENSO activity.

Our conclusions in this study may be model dependent, which is also subject to model resolution. Meehl et al. (2001) suggested that the vertical resolution of ocean model could have a great impact on ENSO variability. If the vertical resolution is coarse, upwelling can be robust even at a large depth, which would 
bring up more cold water to the surface, contributing to stronger ENSO variability. Bear in mind that the uplift of the TP spanned a very long (geological time scale) period, during which the $\mathrm{CO}_{2}$ concentration was not constant, accompanied by massive oscillations of ice sheets' extents at the orbital time scale (Kürschner et al. 2008). The varying $\mathrm{CO}_{2}$ and ice sheet extent can both affect ENSO behaviors. The impact of model bias on the results in this work is another concern. Unlike observations, the CESM exhibits linear ENSO, with SST skewness near zero in the tropical Pacific. This bias is a common feature in the CMIP3 and CMIP5 models, which may come from the westerly wind bursts (Levine et al. 2016), the time-mean zonal winds (Zhang and Sun 2014), and the weak nonlinear interactions, such as atmospheric convection, evaporation, wind response to SST anomalies, zonal advection, and thermocline-surface coupling (Guilyardi et al. 2009b; Sun et al. 2016). By employing a nonlinear model in simulating the observed ENSO asymmetry, Liang et al. (2017), however, showed that the nonlinear heating term does not guarantee the oscillation in the system to possess positive asymmetry. This work underscores the difficulty of simulating the observed ENSO asymmetry by CMIP5 models. In addition, the mean SST pattern from the CESM (Fig. 14 in Yang et al. 2020) shows an excessive cold tongue in the eastern tropical Pacific compared with observation. This bias will lead to enhanced cooling via oceanic upwelling, mixing, and latent heat flux to the atmosphere (Guilyardi et al. 2009b). The excessive cold tongue may also lead to the lack of asymmetry of ENSO variability (Sun et al. 2006, 2013).

The westward extent of simulated ENSO variability is another problem in CESM (Figs. 3a,e). This may be due to the westward displacement of the equatorial trade wind in the western Pacific. This is also a systematic bias among many CMIP5 models (Taschetto et al. 2014). The bias of atmospheric convection scheme in CESM may also affect the sensitivity of surface wind stress to SST perturbation, and thus ENSO amplitude. This study should be regarded as an idealized study designed to explore ENSO magnitude change resulting exclusively from the TP uplift, rather than an attempt to quantify the paleoclimatic ENSO evolution for a specific geological period, because it is difficult to reconstruct various boundary conditions for a specific geological time. ENSO behaviors and related mechanisms under the TP uplift need to be scrutinized using other coupled models in future.

Acknowledgments. This work is supported by the NSF of China (91737204, 41725021, and 41376007) with the financial support from the China Scholarship Council of Ministry of Education. We are also grateful to invaluable suggestions from three reviewers. The experiments were performed on the supercomputers at the LaCOAS, Peking University and at the National Supercomputer Center in Tianjin (Tian-He No. 1).

\section{REFERENCES}

Abe, M., T. Yasunari, and A. Kitoh, 2004: Effects of large-scale orography on the coupled atmosphere-ocean system in the tropical Indian and Pacific Oceans in boreal summer. J. Meteor. Soc. Japan, 82, 745-759, https://doi.org/10.2151/JMSJ.2004.745.

An, S.-I., and F.-F. Jin, 2004: Nonlinearity and asymmetry of ENSO. J. Climate, 17, 2399-2412, https://doi.org/10.1175/15200442(2004)017<2399:NAAOE $>2.0 . C O ; 2$.

An, Z. S., J. E. Kutzbach, W. L. Prell, and S. C. Porter, 2001: Evolution of Asian monsoons and phased uplift of the Himalaya-Tibetan Plateau since late Miocene times. Nature, 411, 62-66, https://doi.org/10.1038/35075035.

Ashok, K., S. K. Behera, S. A. Rao, H. Weng, and T. Yamagata, 2007: El Niño Modoki and its possible teleconnection. J. Geophys. Res., 112, C11007, https://doi.org/10.1029/2006JC003798.

Barnett, T. P., D. W. Pierce, M. Latif, D. Dommenget, and R. Saravanan, 1999: Interdecadal interactions between the tropics and midlatitudes in the Pacific basin. Geophys. Res. Lett., 26, 615-618, https://doi.org/10.1029/1999GL900042.

Battisti, D. S., and A. C. Hirst, 1989: Interannual variability in a tropical atmosphere-ocean model: Influence of the basic state, ocean geometry and nonlinearity. J. Atmos. Sci., 46, 1687-1712, https:// doi.org/10.1175/1520-0469(1989)046<1687:IVIATA >2.0.CO;2.

Burgers, G., and G. J. van Oldenborgh, 2003: On the impact of local feedbacks in the central Pacific on the ENSO cycle. J. Climate, 16, 2396-2407, https://doi.org/10.1175/2766.1.

Cai, W., and Coauthors, 2018: Increased variability of eastern Pacific El Niño under greenhouse warming. Nature, 564, 201206, https://doi.org/10.1038/s41586-018-0776-9.

Capotondi, A., A. Wittenberg, and S. Masina, 2006: Spatial and temporal structure of tropical Pacific interannual variability in 20th century coupled simulations. Ocean Modell., 15, 274-298, https://doi.org/10.1016/j.ocemod.2006.02.004.

Carton, J. A., 1991: Effect of seasonal surface freshwater flux on sea surface temperature in the tropical Atlantic Ocean. J. Geophys. Res., 96, 12 593-12 598, https://doi.org/10.1029/ 91JC01256.

Cerling, T. E., J. M. Harris, B. J. MacFadden, M. G. Leakey, J. Quade, V. Eisenmann, and J. R. Ehleringer, 1997: Global vegetation change through the Miocene/Pliocene boundary. Nature, 389, 153-158, https://doi.org/10.1038/38229.

Chen, L., Y. Yu, and D. Sun, 2013: Cloud and water vapor feedbacks to the El Niño warming: Are they still biased in CMIP5 models? J. Climate, 26, 4947-4961, https://doi.org/10.1175/ JCLI-D-12-00575.1.

, W. Zheng, and P. Braconnot, 2019: Towards understanding the suppressed ENSO activity during mid-Holocene in PMIP2 and PMIP3 simulations. Climate Dyn., 53, 1095-1110, https:// doi.org/10.1007/s00382-019-04637-z.

Clarke, A. J., S. Van Gorder, and G. Colantuono, 2007: Wind stress curl and ENSO discharge/recharge in the equatorial Pacific. J. Phys. Oceanogr., 37, 1077-1091, https://doi.org/10.1175/ JPO3035.1. 
Collins, M., and Coauthors, 2010: The impact of global warming on the tropical Pacific Ocean and El Niño. Nat. Geosci., 3, 391397, https://doi.org/10.1038/ngeo868.

Fallah, B., U. Cubasch, K. Prömmel, and S. Sodoudi, 2016: A numerical model study on the behaviour of Asian summer monsoon and AMOC due to orographic forcing of Tibetan Plateau. Climate Dyn., 47, 1485-1495, https://doi.org/10.1007/ s00382-015-2914-5.

Fedorov, A. V., and S. G. Philander, 2000: Is El Niño changing? Science, 288, 1997-2002, https://doi.org/10.1126/science.288. 5473.1997.

— atmosphere interactions: Bridging measurements and theory for El Niño. J. Climate, 14, 3086-3101, https://doi.org/10.1175/ 1520-0442(2001)014<3086:ASAOTO > 2.0.CO;2.

- S. Hu, M. Lengaigne, and E. Guilyardi, 2015: The impact of westerly wind bursts and ocean initial state on the development, and diversity of El Niño events. Climate Dyn., 44, 13811401, https://doi.org/10.1007/s00382-014-2126-4.

Feng, R., and C. J. Poulsen, 2014: Andean elevation control on tropical Pacific climate and ENSO. Paleoceanography, 29, 795-809, https://doi.org/10.1002/2014PA002640.

Guan, C., and M. J. McPhaden, 2016: Ocean processes affecting the twenty-first-century shift in ENSO SST variability. J. Climate, 29, 6861-6879, https://doi.org/10.1175/JCLI-D15-0870.1.

Guilyardi, E., 2006: El Niño-mean state-seasonal cycle interactions in a multi-model ensemble. Climate Dyn., 26, 329-348, https://doi.org/10.1007/s00382-005-0084-6.

- , P. Braconnot, F. F. Jin, S. T. Kim, M. Kolasinski, T. Li, and I. Musat, 2009a: Atmosphere feedbacks during ENSO in a coupled GCM with a modified atmospheric convection scheme. J. Climate, 22, 5698-5718, https://doi.org/10.1175/ 2009JCLI2815.1.

—_, A. Wittenberg, A. Fedorov, M. Collins, C. Wang, A. Capotondi, G. J. van Oldenborgh, and T. Stockdale, 2009b: Understanding El Niño in ocean-atmosphere general circulation models: Progress and challenges. Bull. Amer. Meteor. Soc., 90, 325-340, https://doi.org/10.1175/2008BAMS2387.1.

Harrison, T. M., P. Copeland, W. S. Kidd, and A. Yin, 1992: Raising Tibet. Science, 255, 1663-1670, https://doi.org/10.1126/science.255. 5052.1663.

Hua, L., D. Z. Sun, and Y. Yu, 2018: Why do we have El Niño: Quantifying a diabatic and nonlinear perspective using observations. Climate Dyn., 52, 6705-6717, https://doi.org/10.1007/ s00382-018-4541-4.

Huang, B., and Coauthors, 2015: Extended reconstructed sea surface temperature version 4 (ERSST.v4). Part I: Upgrades and intercomparisons. J. Climate, 28, 911-930, https://doi.org/ 10.1175/JCLI-D-14-00006.1.

Huber, M., and R. Caballero, 2003: Eocene El Niño: Evidence for robust tropical dynamics in the "hothouse". Science, 299, 877881, https://doi.org/10.1126/science.1078766.

Hunke, E. C., and W. H. Lipscomb, 2010: CICE: The Los Alamos Sea Ice Model, documentation and software user's manual version 4.1. Los Alamos National Laboratory Rep. LA-CC06-012, 76 pp.

Im, S.-H., S.-I. An, S.-T. Kim, and F.-F. Jin, 2015: Feedback processes responsible for El Niño-La Niña amplitude asymmetry. Geophys. Res. Lett., 42, 5556-5563, https://doi.org/10.1002/ 2015 GL064853.

Jin, F.-F., 1997: An equatorial ocean recharge paradigm for ENSO. Part I: Conceptual model. J. Atmos. Sci., 54, 811-829,
https://doi.org/10.1175/1520-0469(1997)054<0811:AEORPF> 2.0.CO;2.

_ S. T. Kim, and L. Bejarano, 2006: A coupled-stability index for ENSO. Geophys. Res. Lett., 33, L23708, https://doi.org/ 10.1029/2006GL027221.

Kang, X., R. Huang, Z. Wang, and R.-H. Zhang, 2014: Sensitivity of ENSO variability to Pacific freshwater flux adjustment in the Community Earth System Model. Adv. Atmos. Sci., 31, 1009-1021, https://doi.org/10.1007/s00376-014-3232-2.

Kao, H.-Y., and J.-Y. Yu, 2009: Contrasting eastern-Pacific and central-Pacific types of ENSO. J. Climate, 22, 615-632, https:// doi.org/10.1175/2008JCLI2309.1.

Kim, S. T., and F.-F. Jin, 2011: An ENSO stability analysis. Part II: Results from the twentieth and twenty-first century simulations of the CMIP3 models. Climate Dyn., 36, 1609-1627, https://doi.org/10.1007/s00382-010-0872-5.

—, W. Cai, F.-F. Jin, A. Santoso, L. Wu, E. Guilyardi, S.-I. An, 2014: Response of El Niño sea surface temperature variability to greenhouse warming. Nat. Climate Change, 4, 786-790, https://doi.org/10.1038/nclimate2326.

Kirtman, B. P., and P. S. Schopf, 1998: Decadal variability in ENSO predictability and prediction. J. Climate, 11, 2804-2822, https:// doi.org/10.1175/1520-0442(1998)011<2804:DVIEPA>2.0.CO;2.

Kitoh, A., 1997: Mountain uplift and surface temperature changes. Geophys. Res. Lett., 24, 185-188, https://doi.org/10.1029/96GL03953. , 2007: ENSO modulation by mountain uplift. Climate Dyn., 28, 781-796, https://doi.org/10.1007/s00382-006-0209-6.

Kleeman, R., J. P. McCreary Jr., and B. A. Klinger, 1999: A mechanism for generating ENSO decadal variability. Geophys. Res. Lett., 26, 1743-1746, https://doi.org/10.1029/1999GL900352.

Knutson, T. R., S. Manabe, and D. Gu, 1997: Simulated ENSO in a global coupled ocean-atmosphere model: Multidecadal amplitude modulation and $\mathrm{CO}_{2}$ sensitivity. J. Climate, 10, 138 161, https://doi.org/10.1175/1520-0442(1997)010<0138:SEIAGC > 2.0.CO;2.

Kug, J. S., and I. S. Kang, 2006: Interactive feedback between ENSO and the Indian Ocean. J. Climate, 19, 1784-1801, https://doi.org/10.1175/JCLI3660.1.

Kürschner, W. M., Z. Kvaček, and D. L. Dilcher, 2008: The impact of Miocene atmospheric carbon dioxide fluctuations on climate and the evolution of terrestrial ecosystems. Proc. Natl. Acad. Sci. USA, 105, 449-453, https://doi.org/10.1073/pnas. 0708588105.

Latif, M., A. Sterl, E. Maier-Reimer, and M. Junge, 1993: Structure and predictability of the El Niño/Southern Oscillation phenomenon in a coupled ocean-atmosphere general circulation model. J. Climate, 6, 700-708, https://doi.org/10.1175/15200442(1993)006<0700:SAPOTE $>2.0 . C O ; 2$.

Lawrence, D. M., K. W. Oleson, M. G. Flanner, C. G. Fletcher, P. J. Lawrence, S. Levis, S. C. Swenson, and G. B. Bonan, 2012: The CCSM4 land simulation, 1850-2005: Assessment of surface climate and new capabilities. J. Climate, 25, 2240-2260, https:// doi.org/10.1175/JCLI-D-11-00103.1.

Levine, A., F.-F. Jin, and M. J. McPhaden, 2016: Extreme noiseextreme El Niño: How state-dependent noise forcing creates El Niño-La Niña asymmetry. J. Climate, 29, 5483-5499, https://doi.org/10.1175/JCLI-D-16-0091.1.

Li, T., and T. F. Hogan, 1999: The role of the annual-mean climate on seasonal and interannual variability of the tropical Pacific in a coupled GCM. J. Climate, 12, 780-792, https://doi.org/ 10.1175/1520-0442(1999)012<0780:TROTAM >2.0.CO;2.

Liang, J., X.-Q. Yang, and D.-Z. Sun, 2012: The effect of ENSO events on the tropical Pacific mean climate: Insights from an 
analytical model. J. Climate, 25, 7590-7606, https://doi.org/ 10.1175/JCLI-D-11-00490.1.

,-- , and -2017 : Factors determining the asymmetry of ENSO. J. Climate, 30, 6097-6106, https://doi.org/10.1175/ JCLI-D-16-0923.1.

Liu, Z., Z. Lu, X. Wen, B. Otto-Bliesner, A. Timmermann, and K. Cobb, 2014: Evolution and forcing mechanisms of El Niño over the past 21,000 years. Nature, 515, 550-553, https:// doi.org/10.1038/nature13963.

Lowenstein, T. K., and R. V. Demicco, 2006: Elevated Eocene atmospheric $\mathrm{CO}_{2}$ and its subsequent decline. Science, $\mathbf{3 1 3}$, 1928, https://doi.org/10.1126/science.1129555.

Lu, Z., Z. Liu, and J. Zhu, 2016: Abrupt intensification of ENSO forced by deglacial ice-sheet retreat in CCSM3. Climate Dyn., 46, 1877-1891, https://doi.org/10.1007/s00382-015-2681-3.

Lübbecke, J. F., and M. J. McPhaden, 2014: Assessing the twentyfirst-century shift in ENSO variability in terms of the Bjerknes stability index. J. Climate, 27, 2577-2587, https://doi.org/ 10.1175/JCLI-D-13-00438.1.

Maffre, P., J. B. Ladant, Y. Donnadieu, P. Sepulchre, and Y. Goddéris, 2017: The influence of orography on modern ocean circulation. Climate Dyn., 50,1277-1289, https://doi.org/ 10.1007/s00382-017-3683-0.

Manabe, S., and A. J. Broccoli, 1990: Mountains and arid climates of middle latitudes. Science, 247, 192-195, https://doi.org/ 10.1126/science.247.4939.192.

Meehl, G. A., P. R. Gent, J. M. Arblaster, B. L. Otto-Bliesner, E. C. Brady, and A. Craig, 2001: Factors that affect the amplitude of El Niño in global coupled climate models. Climate Dyn., 17, 515-526, https://doi.org/10.1007/PL00007929.

Molnar, P., P. England, and J. Martinod, 1993: Mantle dynamics, uplift of the Tibetan Plateau, and the Indian monsoon. Rev. Geophys., 31, 357-396, https://doi.org/10.1029/93RG02030.

Naiman, Z., P. J. Goodman, J. P. Krasting, S. L. Malyshev, J. L. Russell, R. J. Stouffer, and A. T. Wittenberg, 2017: Impact of mountains on tropical circulation in two Earth system models. J. Climate, 30, 4149-4163, https://doi.org/10.1175/JCLI-D-160512.1.

Neelin, J. D., D. S. Battisti, A. C. Hirst, F. F. Jin, Y. Wakata, T. Yamagata, and S. E. Zebiak, 1998: ENSO theory. J. Geophys. Res., 103, 14 261-14 290, https://doi.org/10.1029/ 97JC03424.

Ogata, T., S.-P. Xie, A. Wittenberg, and D.-Z. Sun, 2013: Interdecadal amplitude modulation of El Niño/Southern Oscillation and its impacts on tropical Pacific decadal variability. J. Climate, 26, 7280-7297, https://doi.org/10.1175/ JCLI-D-12-00415.1.

Park, S., C. S. Bretherton, and P. J. Rasch, 2014: Integrating cloud processes in the Community Atmosphere Model, version 5. J. Climate, 27, 6821-6856, https://doi.org/10.1175/JCLI-D-1400087.1.

Penland, C., and P. Sardeshmukh, 1995: The optimal growth of tropical sea surface temperature anomalies. J. Climate, $\mathbf{8}$, 1999-2024, https://doi.org/10.1175/1520-0442(1995)008<1999: TOGOTS $>2.0 . \mathrm{CO} ; 2$.

Philip, S., and G. J. van Oldenborgh, 2006: Shifts in ENSO coupling processes under global warming. Geophys. Res. Lett., 33, L11704, https://doi.org/10.1029/2006GL026196.

Raymo, M. E., and W. F. Ruddiman, 1992: Tectonic forcing of late Cenozoic climate. Nature, 359, 117-122, https://doi.org/ $10.1038 / 359117 \mathrm{a} 0$

Rea, D. K., H. Snoeckx, and L. H. Joseph, 1998: Late Cenozoic Eolian deposition in the North Pacific: Asian drying,
Tibetan uplift, and cooling of the Northern Hemisphere. Paleoceanography, 13, 215-224, https://doi.org/10.1029/ 98PA00123.

Rodgers, K. B., P. Friederichs, and M. Latif, 2004: Tropical Pacific decadal variability and its relation to decadal modulations of ENSO. J. Climate, 17, 3761-3774, https://doi.org/10.1175/15200442(2004)017<3761:TPDVAI >2.0.CO;2.

Ruddiman, W. F., 2013: Tectonic Uplift and Climate Change. Springer, $535 \mathrm{pp}$.

_, and J. E. Kutzbach, 1989: Forcing of Late Cenozoic Northern Hemisphere climate by plateau uplift in southern Asia and the American West. J. Geophys. Res., 94, 18 409-18 427, https:// doi.org/10.1029/JD094iD15p18409.

Santoso, A., W. Cai, M. England, and S. Phipps, 2011: The role of the Indonesian Throughflow on ENSO dynamics in a coupled climate model. J. Climate, 24, 585-601, https://doi.org/10.1175/ 2010JCLI3745.1.

Schmittner, A., T. A. M. Silva, K. Fraedrich, E. Kirk, and F. Lunkeit, 2011: Effects of mountains and ice sheets on global ocean circulation. J. Climate, 24, 2814-2829, https://doi.org/ 10.1175/2010JCLI3982.1.

Sinha, B., A. T. Blaker, J. J.-M. Hirschi, S. Bonham, M. Brand, S. Josey, R. S. Smith, and J. Marotzke, 2012: Mountain ranges favour vigorous Atlantic meridional overturning. Geophys. Res. Lett., 39, L02705, https://doi.org/10.1029/2011 GL050485.

Smith, R. S., and J. M. Gregory, 2009: A study of the sensitivity of ocean overturning circulation and climate to freshwater input in different regions of the North Atlantic. Geophys. Res. Lett., 36, L15701, https://doi.org/10.1029/2009GL038607.

Su, B., D. Jiang, R. Zhang, P. Sepulchre, and G. Ramstein, 2018: Difference between the North Atlantic and Pacific meridional overturning circulation in response to the uplift of the Tibetan Plateau. Climate Past, 14, 751-762, https://doi.org/10.5194/cp14-751-2018.

Sun, D.-Z., 1997: El Niño: A coupled response to radiative heating? Geophys. Res. Lett., 24, 2031-2034, https://doi.org/10.1029/ 97GL01960.

— , and T. Zhang, 2006: A Regulatory effect of ENSO on the time-mean thermal stratification of the equatorial upper ocean. Geophys. Res. Lett., 33, L07710, https://doi.org/10.1029/ 2005 GL025296.

— , and Coauthors, 2006: Radiative and dynamical feedbacks over the equatorial cold tongue: Results from nine atmospheric GCMs. J. Climate, 19, 4059-4074, https://doi.org/ 10.1175/JCLI3835.1.

— Y. Yu, and T. Zhang, 2009: Tropical water vapor and cloud feedbacks in climate models: A further assessment using coupled simulations. J. Climate, 22, 1287-1304, https://doi.org/ 10.1175/2008JCLI2267.1.

, T. Zhang, Y. Sun, and Y. Yu, 2014: Rectification of El NiñoSouthern Oscillation into climate anomalies of decadal and longer time scales: Results from forced ocean GCM experiments. J. Climate, 27, 2545-2561, https://doi.org/10.1175/JCLID-13-00390.1.

Sun, Y., D.-Z. Sun, L. Wu, and F. Wang, 2013: Western Pacific warm pool and ENSO asymmetry in CMIP3 models. $A d v$. Atmos. Sci., 30, 940-953, https://doi.org/10.1007/s00376-0122161-1.

, F. Wang, and D.-Z. Sun, 2016: Weak ENSO asymmetry due to weak nonlinear air-sea interaction in CMIP5 climate models. Adv. Atmos. Sci., 33, 352-364, https://doi.org/10.1007/ s00376-015-5018-6. 
Taschetto, A., A. S. Gupta, N. C. Jourdain, A. Santoso, C. C. Ummenhofer, and M. H. England, 2014: Cold tongue and warm pool ENSO events in CMIP5: Mean state and future projections. J. Climate, 27, 2861-2885, https://doi.org/10.1175/ JCLI-D-13-00437.1.

Timmermann, A., J. Oberhuber, A. Bacher, M. Esch, M. Latif, and E. Roeckner, 1999: Increased El Niño frequency in a climate model forced by future greenhouse warming. Nature, 398, 694-697, https://doi.org/10.1038/19505.

Vecchi, G. A., and B. J. Soden, 2007: Global warming and the weakening of the tropical circulation. J. Climate, 20, 43164340, https://doi.org/10.1175/JCLI4258.1.

Vega-Westhoff, B., and R. Sriver, 2017: Analysis of ENSO's response to unforced variability and anthropogenic forcing using CESM. Sci. Rep., 7, 18047, https://doi.org/10.1038/s41598-01718459-8.

Wang, C., and J. Picaut, 2004: Understanding ENSO physics-A review. Earth's Climate: The Ocean-Atmosphere Interaction, Geophys. Monogr., Vol. 147, Amer. Geophys. Union, 21-48.

Wang, W., and M. J. McPhaden, 2000: The surface-layer heat balance in the equatorial Pacific Ocean. Part II: Interannual variability. J. Phys. Oceanogr., 30, 2989-3008, https://doi.org/ 10.1175/1520-0485(2001)031<2989:TSLHBI > 2.0.CO;2.

Wen, Q., and H. Yang, 2020: Investigating the role of the Tibetan Plateau in the formation of Pacific meridional overturning circulation. J. Climate, 33, 3603-3617, https://doi.org/10.1175/JCLI-D-19-0206.1.
Yang, H., and Q. Zhang, 2008: Anatomizing the ocean's role in ENSO changes under global warming. J. Climate, 21, 65396555, https://doi.org/10.1175/2008JCLI2324.1.

—, Q. Li, K. Wang, Y. Sun, and D. Sun, 2015: Decomposing the meridional heat transport in the climate system. Climate Dyn., 44, 2751-2768, https://doi.org/10.1007/s00382-014-2380-5.

— - X. Shen, J. Yao, and Q. Wen, 2020: Portraying the impact of the Tibetan Plateau on global climate. J. Climate, 33, 35653583, https://doi.org/10.1175/JCLI-D-18-0734.1.

Zebiak, S. E., and M. A. Cane, 1987: A model El Niño-Southern Oscillation. Mon. Wea. Rev., 115, 2262-2278, https://doi.org/ 10.1175/1520-0493(1987)115<2262:AMENO>2.0.CO;2.

Zelle, H., G. Appeldoorn, G. Burgers, and G. J. van Oldenborgh, 2004: The relationship between sea surface temperature and thermocline depth in the eastern equatorial Pacific. J. Phys. Oceanogr., 34, 643-655, https://doi.org/10.1175/2523.1.

Zhang, Q., Y. Guan, and H. Yang, 2008: ENSO amplitude change in observation and coupled models. Adv. Atmos. Sci., 25, 361366, https://doi.org/10.1007/s00376-008-0361-5.

Zhang, R., and T. L. Delworth, 2005: Simulated tropical response to a substantial weakening of the Atlantic thermohaline circulation. J. Climate, 18, 1853-1860, https://doi.org/10.1175/ JCLI3460.1.

Zhang, T., and D.-Z. Sun, 2014: ENSO asymmetry in CMIP5 models. J. Climate, 27, 4070-4093, https://doi.org/10.1175/ JCLI-D-13-00454.1. 